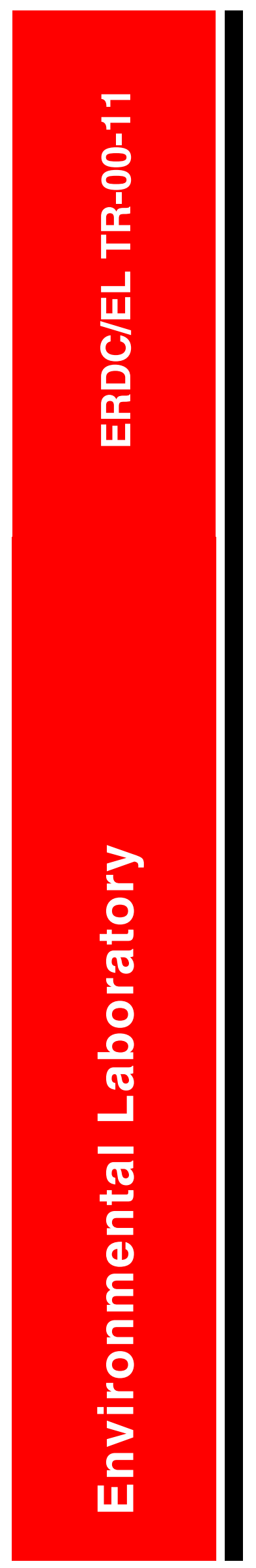

Installation Restoration Research Program

Adsorption and Transformation of Explosives in Low-Carbon Aquifer Soils

Cynthia B. Price, James M. Brannon, Sally L. Yost,

and Charolett A. Hayes

US Army Corps of Engineers ${ }_{\circledast}$

Engineer Research and Development Center

September 2000

Approved for public release; distribution is unlimited. 
The contents of this report are not to be used for advertising, publication, or promotional purposes. Citation of trade names does not constitute an official endorsement or approval of the use of such commercial products.

The findings of this report are not to be construed as an official Department of the Army position, unless so designated by other authorized documents. 


\section{Adsorption and Transformation of Explosives in Low-Carbon Aquifer Soils}

by Cynthia B. Price, James M. Brannon

Environmental Laboratory

U.S. Army Engineer Research and Development Center 3909 Halls Ferry Road

Vicksburg, MS 39180-6199

Sally L. Yost

DynTel Corporation

17 Executive Park Drive

Suite 115

Atlanta, GA 30329

Charolett A. Hayes

AScl Corporation

1365 Beverly Road

McLean, VA 22101

Final report

Approved for public release; distribution is unlimited

Prepared for U.S. Army Corps of Engineers

Washington, DC 20314-1000 


\section{Engineer Research and Development Center Cataloging-in-Publication Data}

Adsorption and transformation of explosives in low-carbon aquifer soils / by Cynthia B. Price ... [et al.] ; prepared for U.S. Army Corps of Engineers.

33 p. : ill. ; 28 cm. -- (ERDC/EL ; TR-00-11)

Includes bibliographic references.

1. Explosives, Military -- Environmental aspects. 2. Soil remediation. 3. Hazardous wastes -Natural attenuation. I. Price, Cynthia B. II. United States. Army. Corps of Engineers. III. Engineer Research and Development Center (U.S.) IV. Environmental Laboratory (U.S.) V. Series: ERDC/EL TR ; 00-11.

TA7 E8 no.ERDC/EL TR-00-11 


\section{Contents}

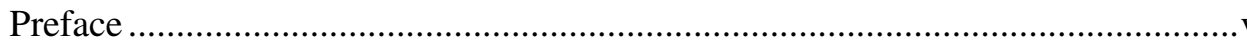

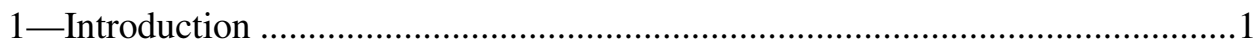

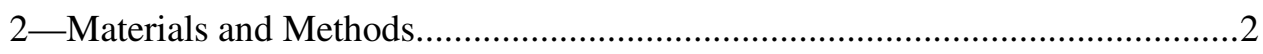

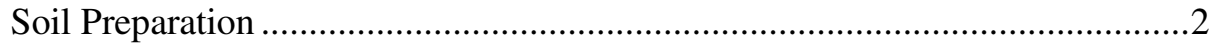

Selection of Energy Source for Eh/pH Incubations ........................................ 3

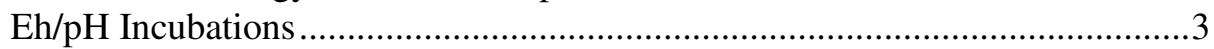

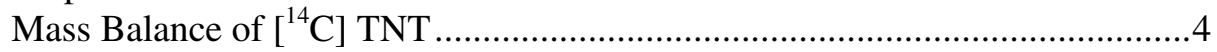

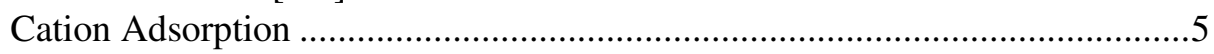

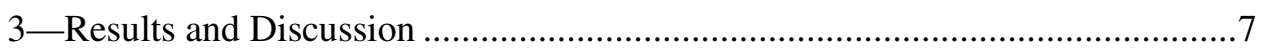

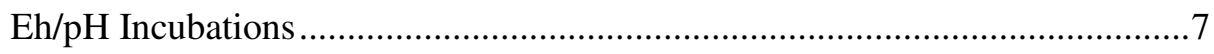

The effects of Eh and pH on TNT stability ...........................................

Effects of Eh on the nature and rate of formation of TNT

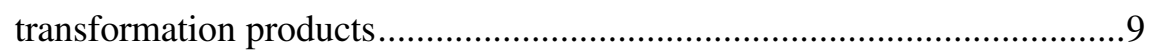

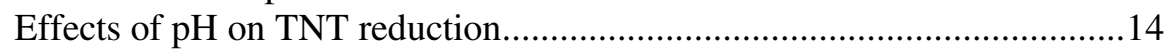

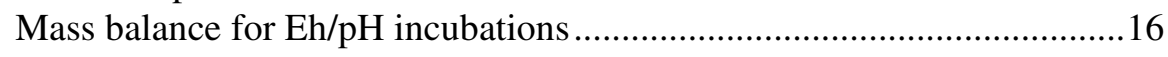

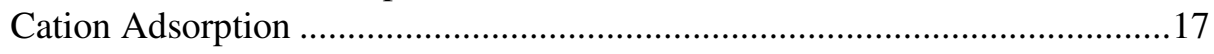

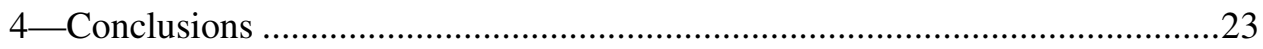

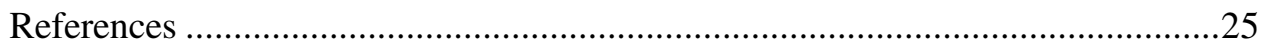

SF 298

\section{List of Figures}

Figure 1. System used to control Eh and $\mathrm{pH}$ over time....................................

Figure 2. TNT aqueous concentrations over time at each Eh and $\mathrm{pH}$ condition .8

Figure 3. TNT aqueous concentrations in glucose-treated and -untreated tests 
Figure 4. Transformation product aqueous concentrations $30 \mathrm{~min}$ after addition of $15 \mathrm{mg}$ TNT.

Figure 5. Transformation product aqueous concentrations $24 \mathrm{hr}$ after addition of $15 \mathrm{mg}$ TNT.

Figure 6. TNT and its transformation products aqueous concentrations in tests conducted with aquifer and surface soils

Figure 7. TNT and its transformation products in solution in the aquifer soil at each $\mathrm{pH}$ over time at $-150 \mathrm{mV}$ .16

Figure 8. TNT and its transformation products in solution at each $\mathrm{pH}$ over time at $+150 \mathrm{mV}$

Figure 9. TNT and its transformation products in solution at each $\mathrm{pH}$ over time at $+450 \mathrm{mV}$ .18

Figure 10. TNT sorption coefficients in homoionic montmorillonite treatments

Figure 11. TNT, RDX, and HMX sorption in homoionic and untreated LAAP-D soil .21

Figure 12. Correlation of TNT K${ }^{+}$and $\mathrm{NH}_{4}{ }^{+}$distribution coefficients with CEC .22

\section{List of Tables}

Table 1. Physical Characteristics of LAAP Aquifer Soils and Clay Minerals ....2

Table 2. First-Order Disappearance Coefficients $k$, Linear Regression Coefficients, and Half-life for TNT Under Controlled Redox Potential and $\mathrm{pH}$ Conditions $(\mathrm{pH}=7)$ in the Presence and Absence of Glucose

Table 3. Mass, mg, of Transformation Products above Detection Limits in Solution and Soil 11 Days after Addition of $15 \mathrm{mg}$ TNT

Table 4. Percent Recoveries of Radioactivity in Tests Conducted with an Aquifer Soil and a Surface Soil

Table 5. TNT Distribution Coefficients $K_{d}$, L/kg, and Associated Linear Regression Coefficients $r^{2}$ for Homoionic and Untreated Aquifer Soils and Clays 


\section{Preface}

The work reported herein was conducted by the Environmental Laboratory (EL), Vicksburg, MS, of the Engineer Research and Development Center (ERDC) for Headquarters, U.S. Army Corps of Engineers (HQUSACE). The research was conducted as part of the Installation Restoration Research Program (IRRP) and the Enviromental Quality Basic Research Program. Dr. M. John Cullinane, EL, was the IRRP Program Manager. Dr. Clem Meyer was the IRRP Coordinator at the Directorate of Research and Development, HQUSACE.

This report was prepared by Ms. Cynthia B. Price and Dr. James M. Brannon, Ecosystem Processes and Effects Branch (EPEB), Environmental Processes and Effects Division (EPED), EL; Ms. Sally L. Yost, DynTel Corporation; and Ms. Charolett A. Hayes, AScI Corporation. The authors wish to acknowledge Ms. Carrie Handley, EPEB, for technical assistance. Technical reviews were provided by Dr. Judith C. Pennington and Mr. David Ringleberg, EPED.

The study was conducted under the direct supervision of Dr. Richard E. Price, Chief, EPED, and under the general supervision of Dr. John Keeley, Acting Director, EL.

At the time of publication of this report, Dr. James R. Houston was Director of ERDC, and COL James S. Weller, EN, was Commander.

This report should be cited as follows:

Price, C. B., Brannon, J. M., Yost, S. L., and Hayes, C. A. (2000). "Adsorption and transformation of explosives in low-carbon aquifer soils," ERDC/EL TR-00-11, Engineer Research and Development Center, Vicksburg, MS.

The contents of this report are not to be used for advertising, publication, or promotional purposes. Citation of trade names does not constitute an official endorsement or approval for the use of such commercial products. 


\section{Introduction}

The explosives 2,4,6-trinitrotoluene (TNT), 1,3,5-trinitro-1,3,5hexahydrotriazine (RDX), and octahydro-1,3,5,7-tetranitro-1,3,5,7-tetrazocine (HMX) have been widely used in manufacturing and in loading, assembling, and packaging of munitions for many decades. Disposal processes from these operations have contaminated soil and groundwater at many active and inactive munitions sites.

The effects of redox potential (Eh) and $\mathrm{pH}$ on the sorption and transformation of explosives in surface soils have been documented (Price, Brannon, and Hayes 1997; Price, Brannon, and Yost 1998). Surface soils, which are typically composed of 1 to 3 percent organic carbon, rapidly adsorb and transform TNT under a wide range of Eh and $\mathrm{pH}$ conditions (Price, Brannon, and Hayes 1997). Specific adsorption to clay minerals can also be a significant sorption process in which the magnitude of sorption is affected by the specific cation sorbed (Haderlein, Weissmahr, and Schwarzenbach 1996; Weissmahr et al. 1999). Results of adsorption tests in low-carbon aquifer soils indicate that sorption and transformation of explosives are significantly lower than in surface soils (Pennington and Patrick 1990; Pennington et al. 1999). Although nitroaromatics can be naturally attenuated in aquifer soils, the active processes involved in the transformation of explosives in these soils are not well understood. Therefore, the effects of physicochemical conditions and groundwater quality on the sorption and transformation of explosives were explored in order to understand these mechanisms.

The objective of these investigations was to determine the effects of Eh and $\mathrm{pH}$ on explosives transformation and sorption in aquifer soils under controlled conditions. Changes in specific adsorption of explosives resulting from different groundwater quality were also evaluated to provide process descriptors for modeling these mechanisms. 


\section{Materials and Methods}

\section{Soil Preparation}

Three different aquifer soils obtained from Louisiana Army Ammunition Plant (LAAP), Minden, LA, and two clays (Table 1) were tested for the effects of homoionic substitution on the adsorption of TNT. The LAAP soils composed three of the four main soil types identified in the LAAP aquifer (Pennington et al. 1999). The clays were obtained from Aldrich Chemical Company, Inc., Milwaukee, WI. The effects of redox potential and $\mathrm{pH}$ on the transformation of TNT were investigated using one of the aquifer soils (LAAP-D). The aquifer soils were obtained by excavating approximately $3 \mathrm{cu}$ m of each soil type 1.2 to $3 \mathrm{~m}$ (4 to $10 \mathrm{ft}$ ) below the ground surface. Each soil was transported separately to an offsite location, air dried, sieved through a 3-mm mesh sieve, and homogenized in a cement mixer. Soils containing higher percentages of clay were pulverized prior to sieving. The soils were then packed into new, plastic lined 0.2 -cu-m (55-gal) drums and shipped to the Environmental Laboratory, Vicksburg, MS, U.S. Army Engineer Research and Development Center. Explosives analyses were performed using a modified (ultrasonic extraction) EPA SW-846 Method 8330 (Environmental Protection Agency (EPA) 1990).

\section{Table 1}

Physical Characteristics of LAAP Aquifer Soils and Clay Minerals

\begin{tabular}{|c|c|c|c|c|c|}
\hline Soil & Sand, \% & Silt, \% & Clay, \% & $\begin{array}{l}\text { Cation } \\
\text { Exchange } \\
\text { Capacity } \\
\text { (CEC) } \\
\text { meq/100 g }\end{array}$ & $\begin{array}{l}\text { Total } \\
\text { Organic } \\
\text { Carbon, \% }\end{array}$ \\
\hline LAAP-A & 89 & 5 & 6 & 2.5 & 0.31 \\
\hline LAAP-C & 77 & 11 & 12 & 6.6 & 0.08 \\
\hline LAAP-D & 27 & 41 & 32 & 15.5 & 0.20 \\
\hline Montmorillonite & NA & NA & NA & 27.7 & ND \\
\hline Kaolinite & NA & NA & NA & 3.1 & ND \\
\hline
\end{tabular}




\section{Selection of Energy Source for Eh/pH Incubations}

To determine the ability of various energy sources (sodium acetate, sodium acetate + benzoic acid, sodium acetate + sodium salicylate, glucose, glucose + sodium acetate, fructose, fructose + sodium acetate, sucrose, and sucrose +sodium acetate) to induce and maintain highly reduced $(-150 \mathrm{mV})$ conditions, LAAP-D aquifer soil was incubated with these energy sources at constant $\mathrm{pH}$. Sufficient distilled-deionized water and soil were added to each 2800-ml Fernbach flask to produce a water-to-solids ratio of 18:1 (150 g oven dry weight (ODW) soil in $2600 \mathrm{ml}$ water). Slurries were kept in suspension by magnetic stirring and were maintained at room temperature. At the start of each incubation and periodically thereafter, flasks were supplemented with $1 \mathrm{~g}$ of each energy source. A continuous stream of nitrogen was flushed through each system to promote anaerobic conditions, and $\mathrm{Eh}$ and $\mathrm{pH}$ were monitored continuously over a 3-week period. A pH of 7 was maintained by injection of $1.0 \mathrm{~N} \mathrm{HCl}$ or $1.0 \mathrm{~N} \mathrm{NaOH}$.

Highly reduced conditions were not reached in the systems containing sodium acetate, sodium acetate + benzoic acid, sodium acetate + sodium salicylate, and fructose. Tests containing glucose or sucrose alone and those containing glucose and sucrose + sodium acetate did reach highly reduced conditions, $-350 \mathrm{mV}$ and lower. Glucose was selected as the energy source to use because flasks containing glucose alone reached anaerobic conditions in the first week of incubation and maintained these conditions for the entire incubation period.

\section{Eh/pH Incubations}

Test systems were reestablished as described in the previous section, with glucose added as the energy source at a rate of $1 \mathrm{~g}$ every 4 days to maintain microbial removal of oxygen and other electron acceptors from the systems. The $\mathrm{Eh}$ and $\mathrm{pH}$ of the slurries were maintained using the methods developed by Patrick, Williams, and Moraghan (1973) with some modifications (Brannon 1983). The Eh was monitored by platinum and $\mathrm{Ag}-\mathrm{AgCl}$ electrodes connected to a pH-millivolt meter (Beckman Instruments, Fullerton, CA). The desired Eh was set on a meter relay (Currier and Roser, New Orleans, LA), which by activating an aquarium pump to introduce air into the system when the set point was reached, prevented the Eh from falling below the preset value (Figure 1). To help maintain anaerobic conditions, nitrogen gas was flushed through the system at a rate of approximately $15 \mathrm{ml} / \mathrm{min}$. System $\mathrm{pH}$ was monitored using a combination $\mathrm{pH}$ electrode connected to a separate $\mathrm{pH}$-millivolt meter. The soil suspensions were allowed to incubate and stabilize to the desired $\mathrm{Eh}$ and $\mathrm{pH}$ values for approximately 3 weeks prior to addition of TNT. The study consisted of duplicate tests conducted at 3 Eh levels, $+450 \mathrm{mV}$ (oxidized), $+150 \mathrm{mV}$ (moderately reduced), and $-150 \mathrm{mV}$ (highly reduced), and a range of $3 \mathrm{pH}$ values, 6.0, 7.0, and 8.0.

Following stabilization, $1 \mathrm{ml}$ of methanol containing $15 \mathrm{mg}$ of TNT (equivalent to $5.8 \mathrm{mg} / \mathrm{L}$ in the reactors) was added. All flasks were covered with aluminum foil prior to spiking to prevent photodecomposition of the TNT. The slurries were sampled at $30 \mathrm{~min}, 4 \mathrm{hr}, 24 \mathrm{hr}$, and 11 days for aqueous contaminant 


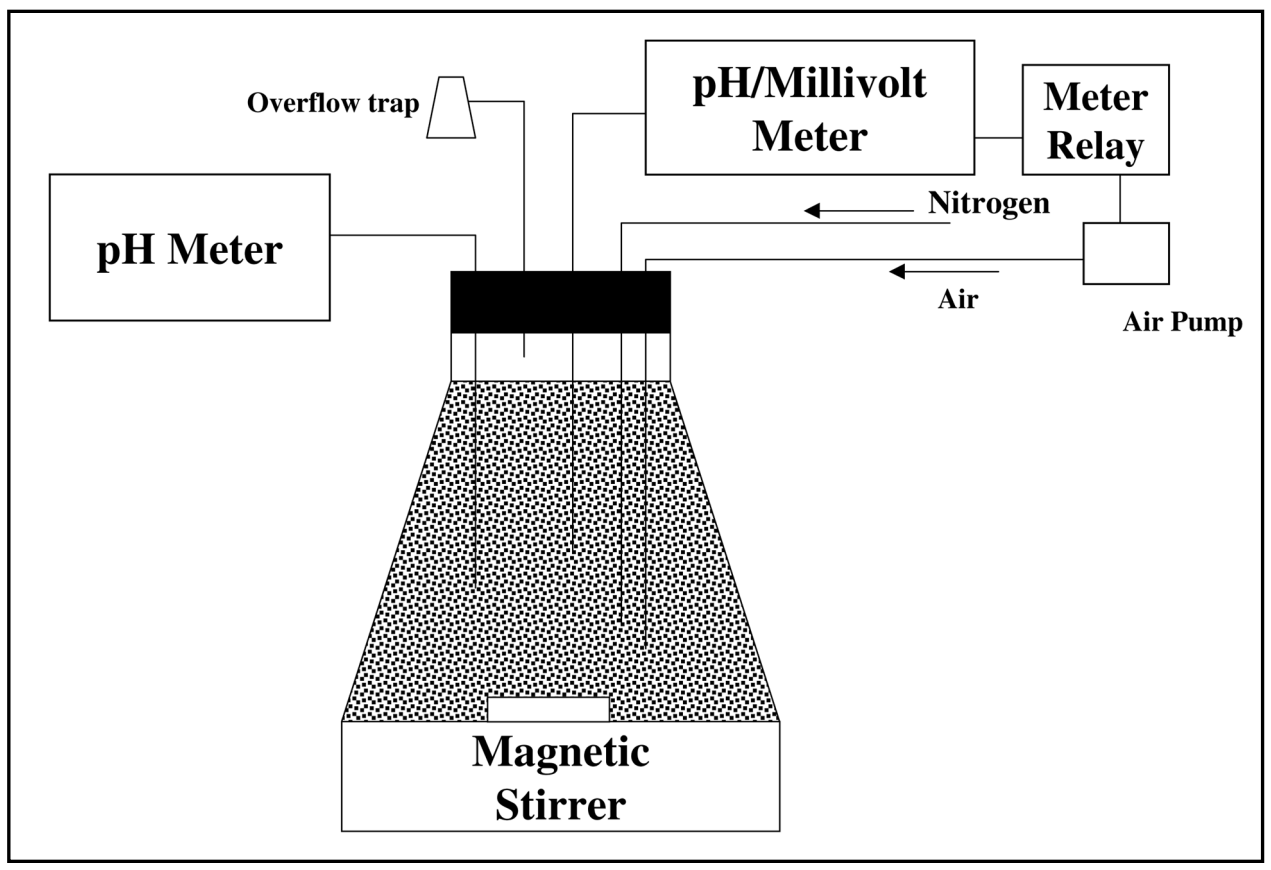

Figure 1. System used to control Eh and $\mathrm{pH}$ over time

concentrations including TNT, 1,3,5-trinitrobenzene (TNB), 1,3-dinitrobenzene (DNB), 4-amino-2,6-dinitrotoluene (4A-DNT), 2-amino-4,6-dinitrotoluene (2ADNT), 2,6-dinitrotoluene (2,6-DNT), 2,4-dinitrotoluene (2,4-DNT) 2,6-diamino4-nitrotoluene (2,6-DANT), 2,4-diamino-6-nitrotoluene (2,4-DANT), 4,4,6,tetranitro-2,2-azoxytoluene (2,2-AZOX), and 2,2'6,6-tetranitro-4,4-azoxytoluene (4,4-AZOX). Analyses were performed according to EPA SW-846 Method 8330 (EPA 1982). Following 11 days of incubation, soils were analyzed for the same parameters as the waters (EPA 1990).

Duplicate $\mathrm{Eh} / \mathrm{pH}$ incubations were also conducted at $+450 \mathrm{mV}$ and $+150 \mathrm{mV}$ at $\mathrm{pH} 7$ to examine the behavior of TNT in the absence of glucose. Incubations were not conducted at $-150 \mathrm{mV}$ because this potential could not be attained in the absence of an added energy source. Experimental conditions and procedures were identical to those described previously.

\section{Mass Balance of $\left[{ }^{14} \mathrm{C}\right] \mathrm{TNT}$}

Mass balance of radiolabeled carbon was determined using uniformly ringlabeled TNT ( $\left.\left[{ }^{14} \mathrm{C}\right] \mathrm{TNT}\right)$ (New England Nuclear Research Products, Boston, MA) having a specific activity of $21.58 \mathrm{mCi} / \mathrm{mmol}$ and a chemical purity $>98$ percent as determined by high-performance liquid chromatography (HPLC). Tests were conducted in triplicate at +450 and $-150 \mathrm{mV}$ at $\mathrm{pH} 7$ using the same experimental design as described previously. Flasks were spiked with 1 part radiolabeled and 99 parts unlabeled TNT to give an overall concentration of $10 \mathrm{ug}$ TNT/g of soil. A bubble trap containing $1 \mathrm{~N} \mathrm{KOH}$ was attached to each flask to trap evolved $\mathrm{CO}_{2}$ and was sampled daily over the 14-day incubation period. The aqueous phase of the incubation flasks was sampled periodically over the 14-day incubation period. 
Soils were sampled on day 14. Radioactivity in the aqueous phase and in the $\mathrm{CO}_{2}$ traps was determined by counting $1 \mathrm{ml}$ of water or $\mathrm{KOH}$ in $15 \mathrm{ml}$ Ultima Gold Liquid Scintillation Cocktail (Packard Instruments, Meridan, CT) on a Packard Tricarb 2500 TR Liquid Scintillation (LS) Counter (Packard Instruments, Meridan, CT). The soil was combusted in a Model 307 Packard Sample Oxidizer (Packard Instruments, Meridan, CT) and the radiolabeled $\mathrm{CO}_{2}$ generated was trapped in Carbo-Sorb and counted in Permafluor Liquid Scintillation Cocktail (Packard Instruments, Meridan, CT) by LS.

\section{Cation Adsorption}

The three aquifer soils and two clays previously described were tested for the effects of homoionic substitution on adsorption of TNT. Haderlein, Weissmahr, and Schwarzenbach (1996) reported no tendency toward specific adsorption of RDX and HMX to clay minerals; therefore, sorption tests with RDX and HMX were limited to LAAP-D soil.

The aquifer soils and clays were rendered homoionic using the cation saturation method of Jackson (1958). Soils and clays were saturated with either calcium $\left(\mathrm{Ca}^{++}\right)$, ammonium $\left(\mathrm{NH}_{4}^{+}\right)$, or potassium $\left(\mathrm{K}^{+}\right)$ions from $1 \mathrm{M}$ solutions of calcium acetate, ammonium acetate, or potassium acetate. Saturation was accomplished by shaking a mixture (6:1 solution to soil) for 30 min followed by centrifugation and addition of fresh ionic solution for a total of three cycles. Upon completion of saturation, the soils and clays were rinsed three times with isopropyl alcohol, using procedures similar to those used for saturation, to remove excess cations and acetate.

Adsorption tests were conducted in triplicate in 25-ml centrifuge tubes containing $4 \mathrm{~g}$ ODW of each of the three aquifer soils and two clays. Tests with TNT were conducted with both the homoionic materials and the unmodified soils and clay minerals. Testing with RDX and HMX was conducted only with LAAP-D. Tests were spiked with $16 \mathrm{ml}$ of distilled deionized water (DDI) containing either TNT or RDX at concentrations of 10, 7.5, 5, 2.5, and $1 \mathrm{mg} / \mathrm{L}$. HMX solution spike concentrations were $2.7,1.98,1.33,0.65$, and $0.26 \mathrm{mg} / \mathrm{L}$.

Solutions of TNT, RDX, and HMX were 1 part radiolabeled to 99 parts unlabeled compound. Radiolabeled compounds were TNT [(ring- $\left.\left.{ }^{14} \mathrm{C}\right) \mathrm{TNT}\right]$ with a specific activity of $21.58 \mathrm{MCi} / \mathrm{mmol}$ and chemical purity of $>98$ percent; RDX $\left[\left(\right.\right.$ ring $\left.-{ }^{14} \mathrm{C}\right)$ RDX] with a specific activity of $4.3 \mathrm{MCi} / \mathrm{mmol}$ and a chemical purity of $>98.4$ percent; and HMX [(ring- $\left.\left.{ }^{14} \mathrm{C}\right) \mathrm{HMX}\right]$ with a specific activity of 8.2 $\mathrm{MCi} / \mathrm{mmol}$ and a radiochemical purity $>97$ percent. All isotopes were obtained from New England Nuclear Research Products, Boston, MA. Tests were equilibrated and the solution phase assayed by LS as described previously.

Stability tests were conducted with unlabeled TNT and RDX to ensure that these compounds remained stable during the course of the adsorption experiments. HMX is known to be stable over a wide range of environmental conditions (Price, Brannon, and Yost 1998). Stability tests were conducted with 25-ml centrifuge tubes containing $4 \mathrm{~g}$ ODW of each of the three aquifer soils and the two clays. Tests with TNT were conducted with both the homoionic soils and 
clays, and with the soils and clays without modification. RDX stability was examined with the LAAP-D soil only. Tests were spiked with $16 \mathrm{ml}$ of DDI containing either TNT or RDX at a concentration of $10 \mathrm{mg} / \mathrm{L}$. Following addition of the test solution, the centrifuge tubes were sealed, shaken for $24 \mathrm{hr}$ on a horizontal shaker at 180 excursions per minute, then centrifuged for $15 \mathrm{~min}$ at 7,400 relative centrifugal force (RCF), and sampled by removing $1 \mathrm{ml}$. Analyses were performed by HPLC for TNT, RDX, and their transformation products according to EPA (EPA 1990). 


\section{Results and Discussion}

\section{Eh/pH Incubations}

\section{The effects of Eh and pH on TNT stability}

TNT was unstable under all Eh or pH conditions tested when glucose was present and was not found in either the aqueous or solid phases at the end of the 11-day incubation period. Unidentified peaks were observed in solution, but attempts to identify these unknown compounds using mass spectroscopy were unsuccessful due to detection limit constraints. These results differ from those seen in similar experiments conducted with a surface soil in which TNT was still present in the soil under moderately reducing to oxidizing conditions $(0,+250$, and $+500 \mathrm{mV}$ ) (Price, Brannon, and Hayes 1997). Under highly reduced conditions $(-150 \mathrm{mV})$, virtually all of the TNT $(<0.03 \mathrm{mg} / \mathrm{L}$ remained $)$ had disappeared from solution within the first $4 \mathrm{hr}$ of incubation (Figure 2a). Under moderately reduced conditions $(+150 \mathrm{mV})$ TNT remained in solution at each $\mathrm{pH}$ up to and through 24 hours of incubation (Figure $2 b$ ). Under oxidized conditions $(+450 \mathrm{mV})$, TNT was present in solution at each $\mathrm{pH}$ through $24 \mathrm{hr}$ of incubation, but had disappeared by 11 days (Figure $2 \mathrm{c}$ ). These results indicate that the addition of water-soluble glucose promoted rapid transformation of TNT.

Processes that remove explosives contaminants from solution can be approximated with first-order kinetics of the form

$$
d c / d t=-k c
$$

where

$$
\begin{aligned}
& c=\text { chemical concentration of the reacting substance, } \mathrm{mg} / \mathrm{L} \\
& t=\text { time }, \mathrm{hr} \\
& k=\text { first-order reaction constant per hour }
\end{aligned}
$$

First-order kinetics then reduces to the equation

$$
\ln \left(c_{0} / c\right)=k t
$$




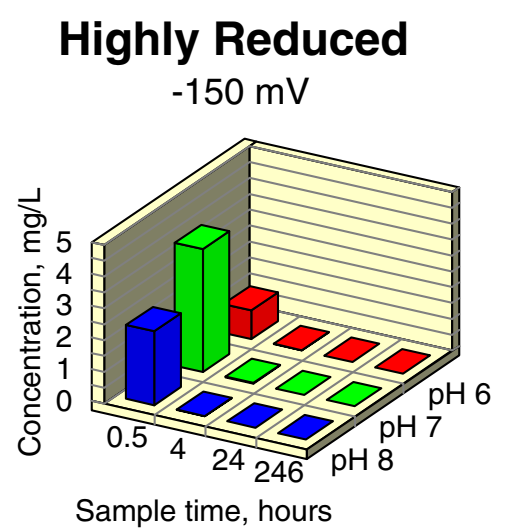

a. Highly reduced

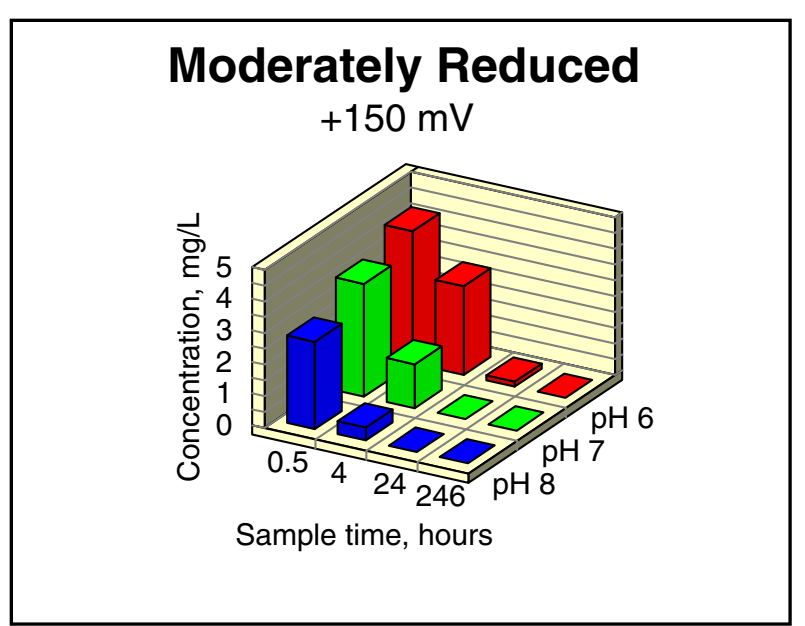

b. Moderately reduced

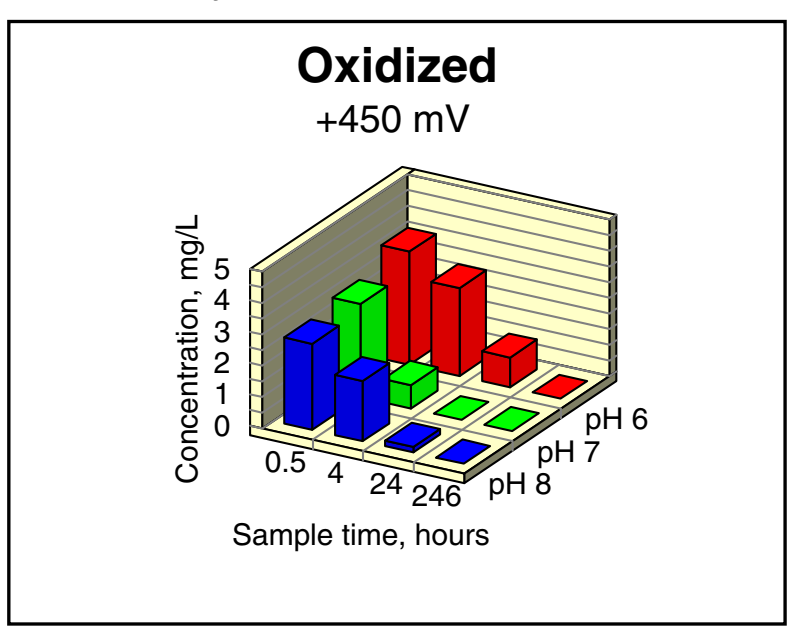

c. Oxidized

Figure 2. TNT aqueous concentrations over time at each Eh and $\mathrm{pH}$ condition 
where $c_{0}$ is the concentration of the reacting substance at time 0 . Once a value of $k$ is obtained, the half-life period of the reacting substance, $t_{1 / 2}$ can be calculated using the equation

$$
t_{1 / 2}=0.693 / k
$$

Results showed that disappearance of TNT in the reactors under controlled Eh and $\mathrm{pH}$ conditions could be adequately described using first-order kinetics (Table 2). The addition of glucose resulted in order of magnitude increases in the rates of TNT disappearance (Figure 3). Approximately 15 percent of the TNT remained in solution at $+150 \mathrm{mV}$ and $+450 \mathrm{mV}$ in the treatments without glucose after 11 days of incubation. These results suggest that the addition of glucose may have stimulated microbial communities capable of transforming TNT, resulting in more rapid loss and/or transformation of TNT than would occur without an added energy source.

\section{Table 2}

First-Order Disappearance Coefficients $k$, Linear Regression Coefficients, and Half-life for TNT Under Controlled Redox Potential and $\mathrm{pH}$ Conditions ( $\mathrm{pH}=7$ ) in the Presence and Absence of Glucose

\begin{tabular}{||l|l|l|l||}
\hline \hline Treatment & $\boldsymbol{k}, \mathbf{h r}^{-1}$ & $\boldsymbol{r}^{2}$ & Half-life, $\mathbf{h r}$ \\
\hline \hline$+150 \mathrm{mV}$ without glucose & 0.007 & 0.81 & 102 \\
\hline$+150 \mathrm{mV}$ with glucose & 0.613 & 0.89 & 1.10 \\
\hline$+450 \mathrm{mV}$ without glucose & 0.008 & 0.87 & 89.0 \\
\hline$+450 \mathrm{mV}$ with glucose & 0.417 & 0.73 & 1.70 \\
\hline
\end{tabular}

\section{Effects of Eh on the nature and rate of formation of TNT transformation products}

TNT transformation product formation was rapid and related to the Eh of the soil system, with lower Eh resulting in greater product concentrations. Following 30 min of incubation, the transformation products 4A-DNT, 2A-DNT, and 4,4AZOX were present in solution at all redox conditions (Figures $4 a, b$, and c). A higher number of products at greater concentrations were found under highly reducing $(-150 \mathrm{mV})$ and moderately reducing $(+150 \mathrm{mV})$ conditions (Figures $4 \mathrm{a}$ and $b$ ). The 4-amino and 2-amino compounds were present under most Eh conditions after $30 \mathrm{~min}$ and $24 \mathrm{hr}$ of incubation. The 4,4-AZOX compound was present in solution at all redox potentials after $30 \mathrm{~min}$ of incubation. The transformation product highest in mass at the 30-min sampling under all Eh conditions was 4,4-AZOX. Concentrations reached $0.77 \mathrm{mg} / \mathrm{L}$ in the $-150 \mathrm{mV}$ test. Twenty-four hours after addition of TNT, the 4,4-AZOX had virtually disappeared from solution in all treatments (Figure 5). These results are similar to 


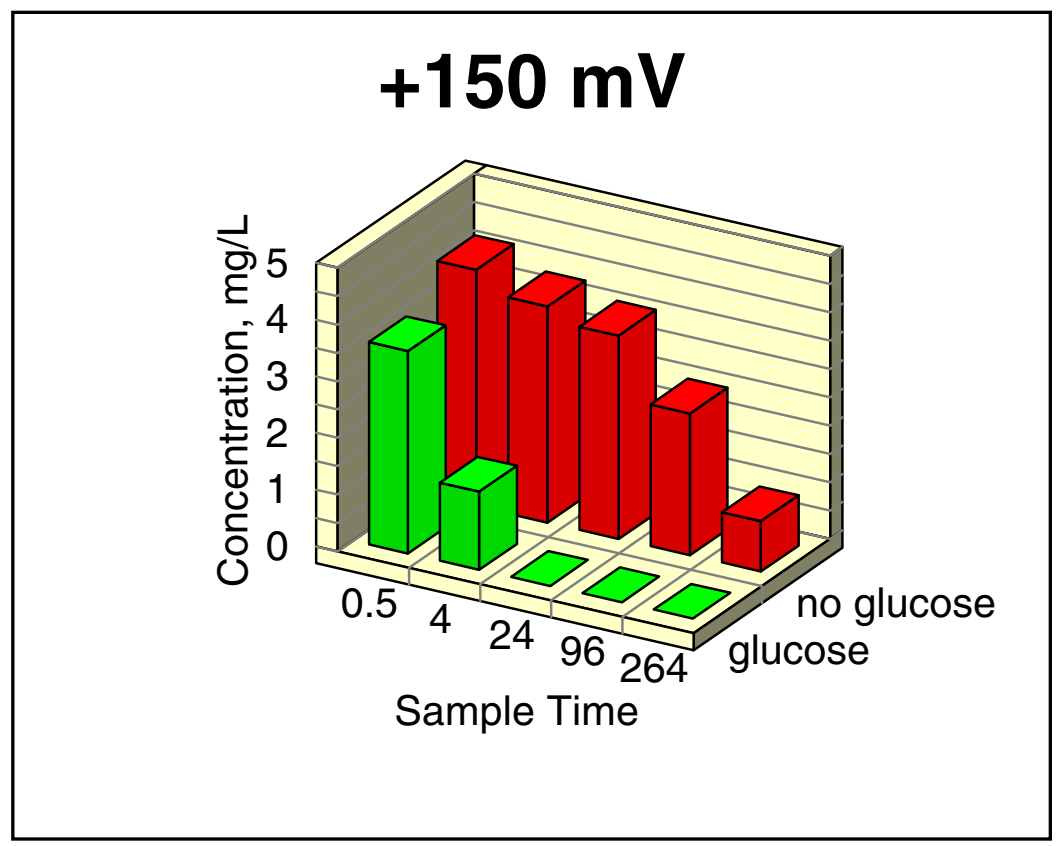

a. $+150 \mathrm{mV}$

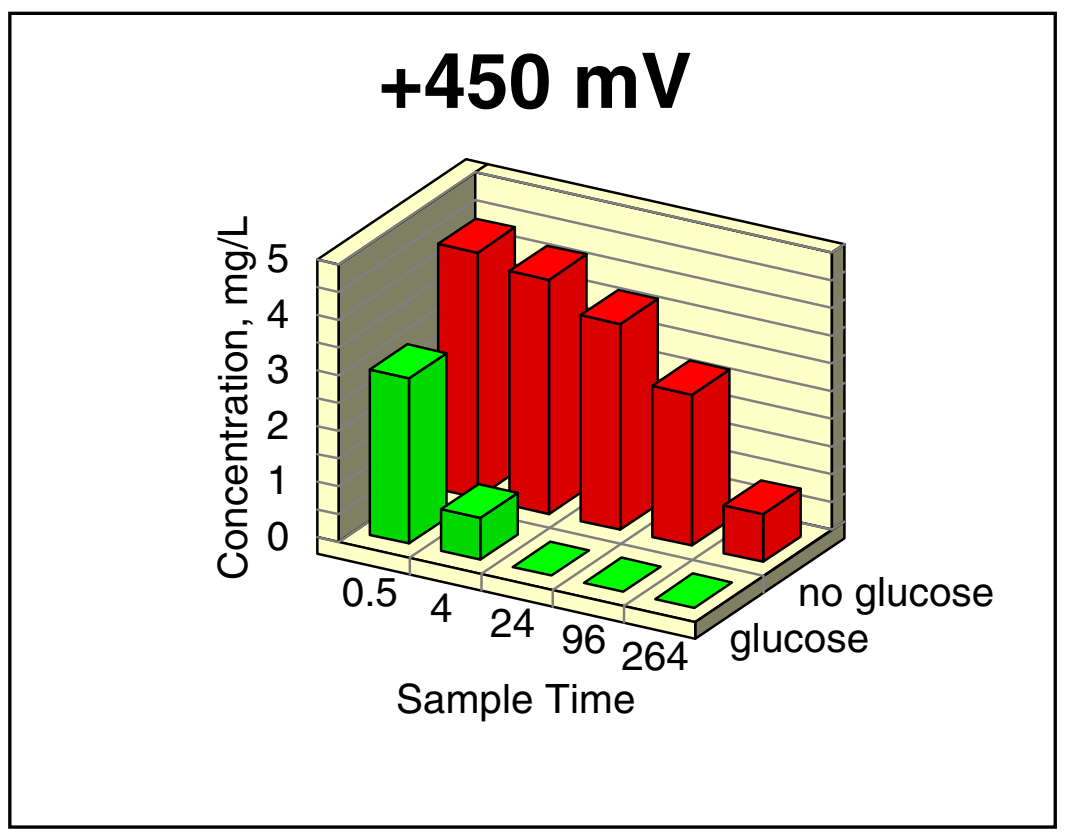

b. $+450 \mathrm{mV}$

Figure 3. TNT aqueous concentrations in glucose-treated and -untreated tests 


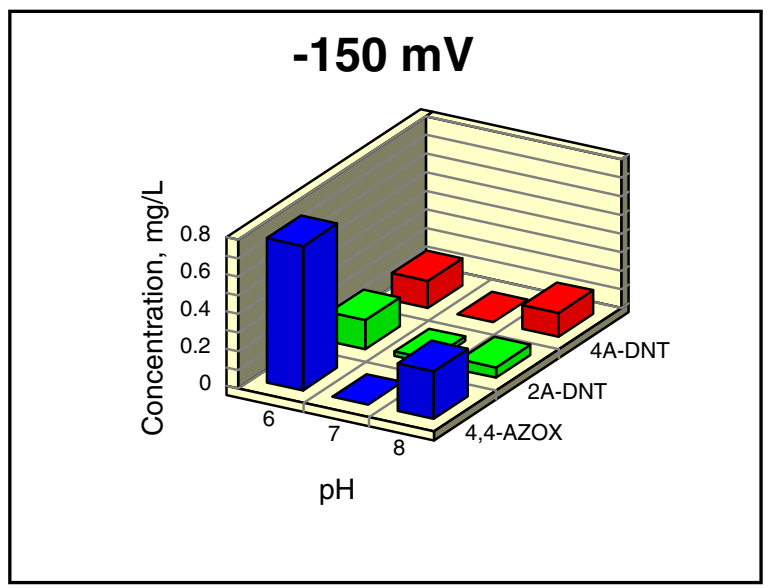

a. $-150 \mathrm{mV}$

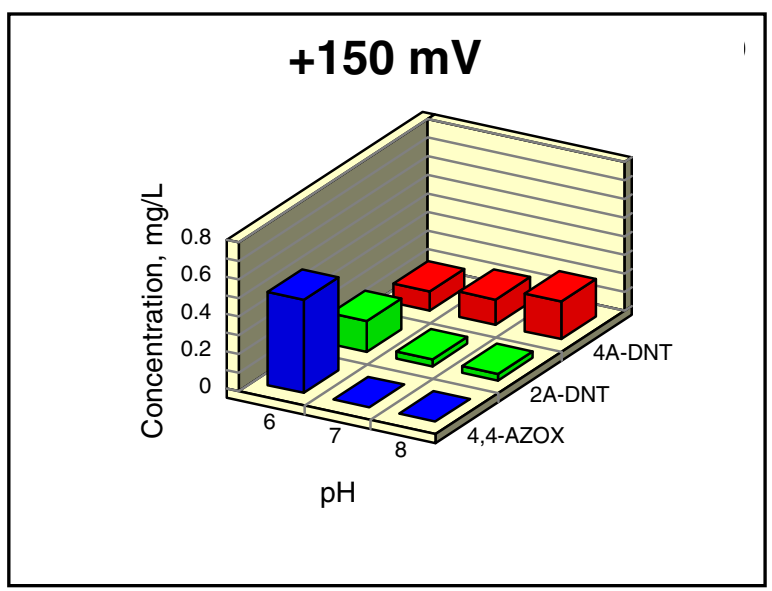

b. $+150 \mathrm{mV}$

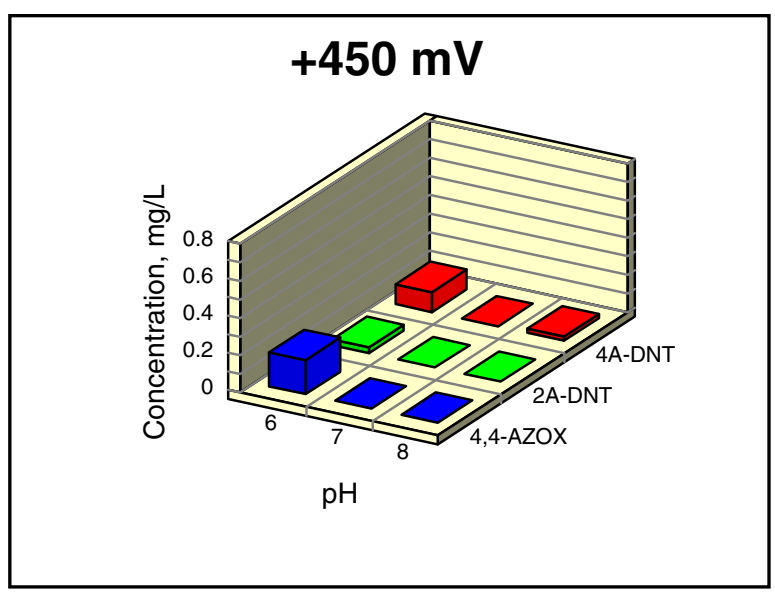

C. $+450 \mathrm{mV}$

Figure 4. Transformation product aqueous concentrations $30 \mathrm{~min}$ after addition of $15 \mathrm{mg}$ TNT 


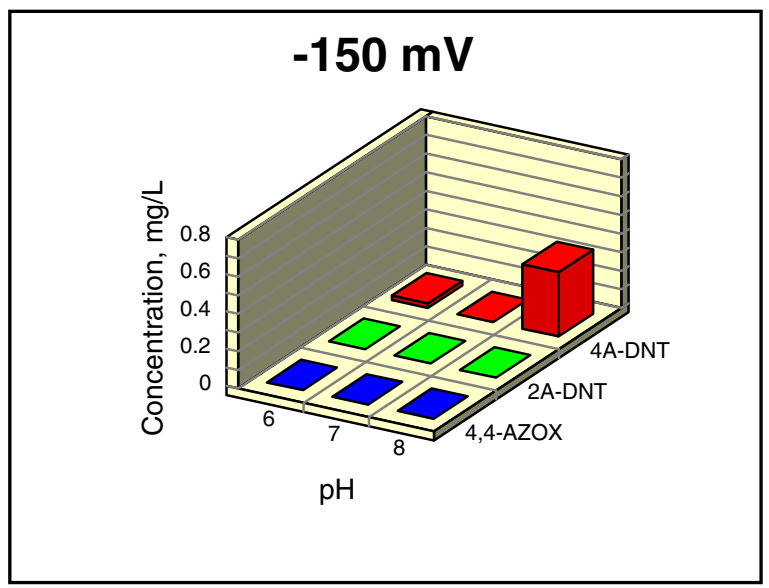

a. $-150 \mathrm{mV}$

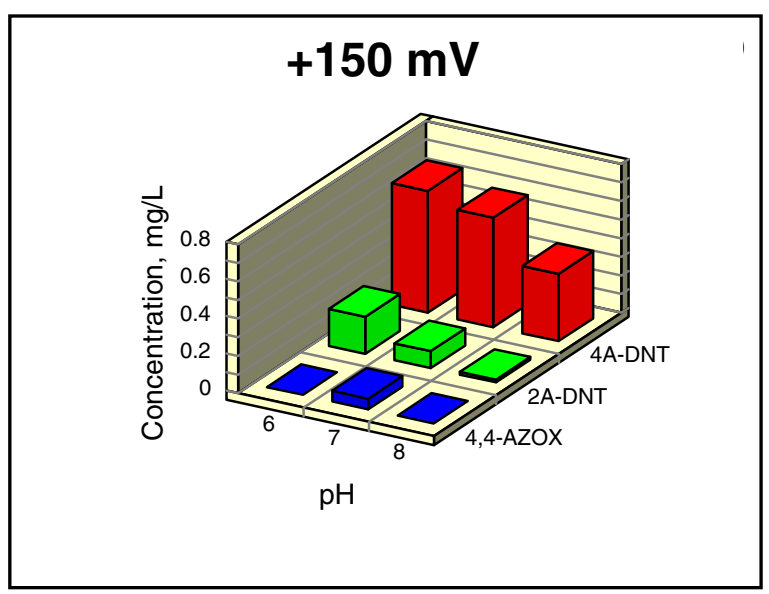

b. $+150 \mathrm{mV}$

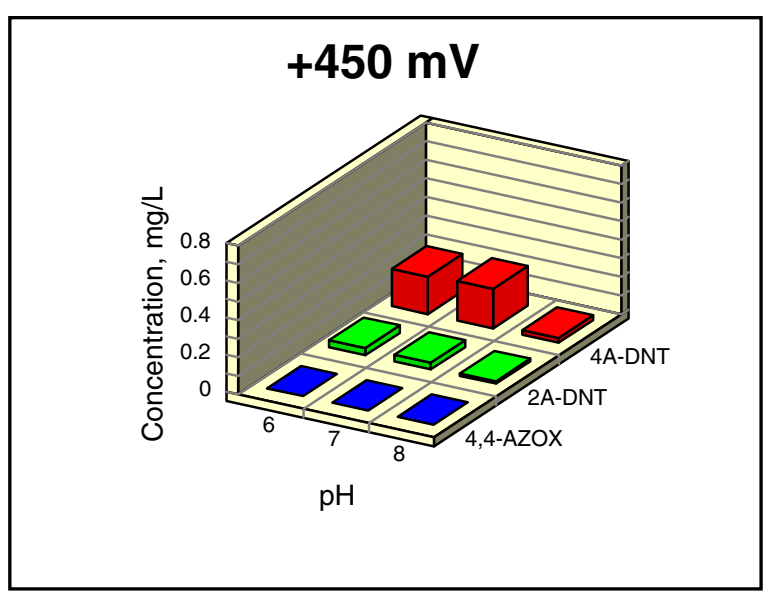

C. $+450 \mathrm{mV}$

Figure 5. Transformation product aqueous concentrations $24 \mathrm{hr}$ after addition of $15 \mathrm{mg}$ TNT 
those reported by Kaplan and Kaplan (1982) where the rapid formation of monoamino compounds, in particular 4A-DNT, is followed by the formation of 4,4-AZOX. The absence of azoxytoluene compounds other than 4,4-AZOX suggests that either formation of the reduction product 4A-DNT was favored since it is the precursor for 4,4-AZOX, or that the 4,4-AZOX compound is more stable than the other azoxytoluenes. Disappearance of transformation products from solution was most rapid under highly reduced conditions. After $24 \mathrm{hr}$, 4A-DNT was the only product present in solution at an Eh of $-150 \mathrm{mV}$ (Figure 5a). Under moderately reducing and oxidizing conditions, the 4A-DNT increased after $24 \mathrm{hr}$ of incubation, but the 4,4-AZOX compound was found only in the $+150 \mathrm{mV}$ test (Figures $5 \mathrm{~b}$ and $\mathrm{c}$ ).

Highly reduced $(-150 \mathrm{mV})$ conditions in investigations conducted with a surface soil (Figure 6a) (Price, Brannon, and Hayes 1997) resulted in the production of a greater number of transformation products, specifically the diamino compounds, than was seen in experiments conducted with the aquifer soil (Figure 6b). The transformation products 4A-DNT, 2A-DNT, 2,6-DANT, and 2,4-DANT were found in solution $24 \mathrm{hr}$ after the addition of TNT in the surface soil (Figure 6a). In contrast the aquifer soil systems, under reduced conditions, yielded only 4A-DNT and 2,4-DANT through the same sampling period (Figure $6 \mathrm{~b}$ ). The longer persistence of transformation products in the surface soil compared with that of the glucose-amended aquifer soil is probably an artifact of increased microbial activity due to the addition of a readily utilizable substrate (glucose) as compared with the less bioavailable complex organic carbon compounds present in the surface soil. These findings are supported by the results showing that TNT and its transformation products persisted longer in aquifer soil that was not amended with glucose (Figure 3).

Another notable difference between investigations conducted with an aquifer or a surface soil was the presence of 2,6-DANT in solution in the surface soil reactors. This compound was not seen in the solution or soil in investigations conducted with the aquifer soil. The absence of 2,6-DANT and presence of 2,4-DANT in conjunction with 4,4-AZOX in the aquifer soil indicate preferential formation of $4 \mathrm{~A}-\mathrm{DNT}$ in the highly reduced aquifer soil. Under aerobic conditions, transformation products were similar in the aquifer and surface soils with only 2A-DNT and 4A-DNT present in solution $24 \mathrm{hr}$ after TNT addition (Figures $6 c$ and d).

Soil analysis revealed greater numbers and higher concentrations of transformation products in both the solution and soil phases under moderately reducing and oxidizing conditions (Table 3 ). The azoxy compound, 4,4-AZOX, which disappeared from solution, remained in the soils under most Eh conditions. The highest recoveries of TNT transformation products were at +150 and $+450 \mathrm{mV}$. TNT was not found in either the soil or solution at the end of the incubation. 


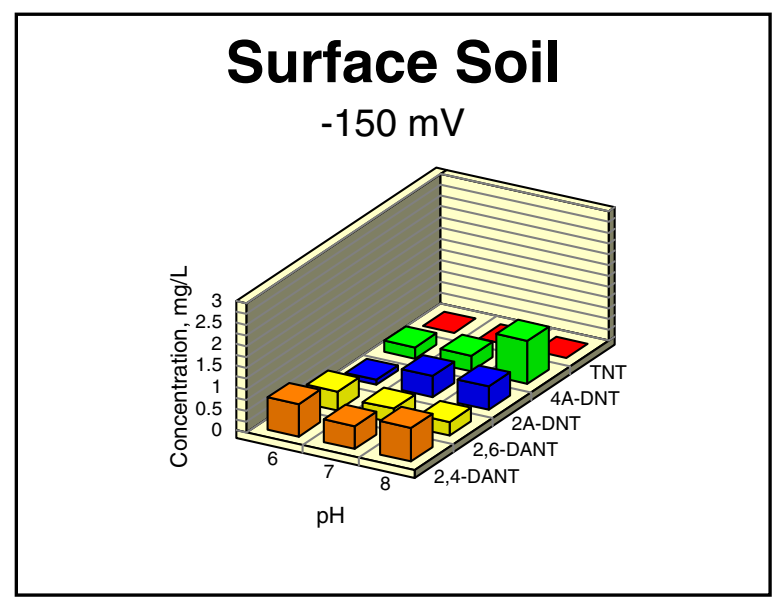

a. Surface soil, $-150 \mathrm{mV}$

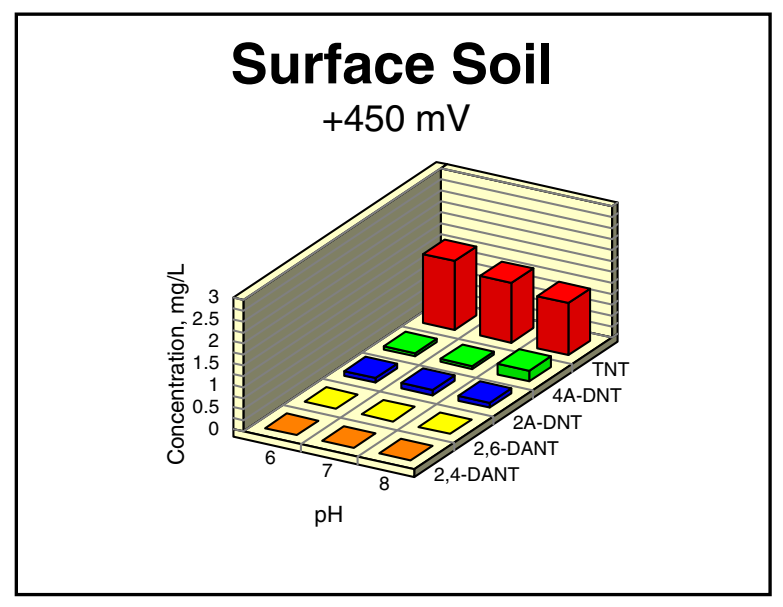

C. Surface soil, $+450 \mathrm{mV}$

\section{Aquifer Soil $-150 \mathrm{mV}$}

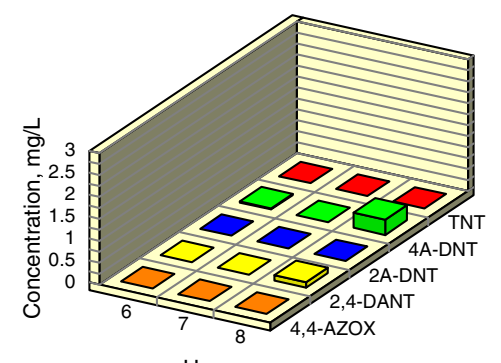

$\mathrm{pH}$

b. Aquifer soil, $-150 \mathrm{mV}$

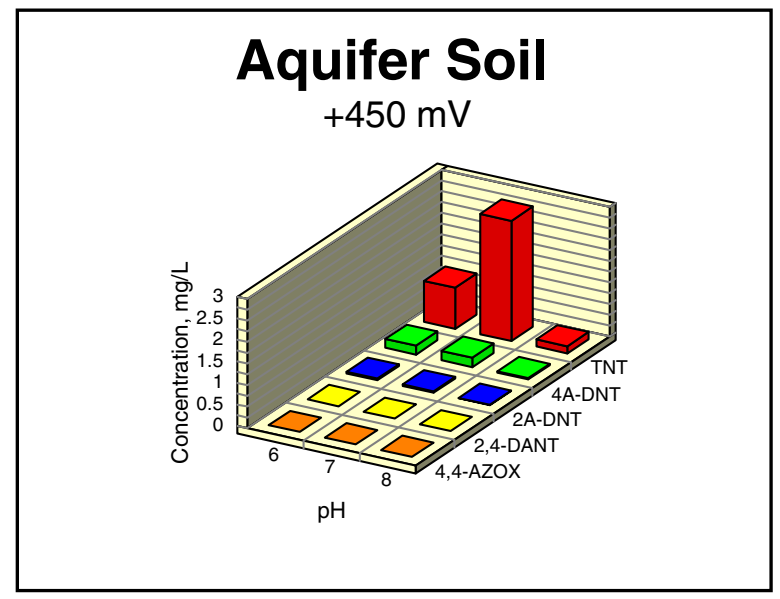

d. Aquifer soil, $+450 \mathrm{mV}$

Figure 6. TNT and its transformation products aqueous concentrations in tests conducted with aquifer and surface soils

\section{Effects of $\mathrm{pH}$ on TNT reduction}

Under highly reduced conditions $(-150 \mathrm{mV}), \mathrm{pH}$ apparently affected the initial concentration of 4,4-AZOX in solution. Samples from reactors maintained at $\mathrm{pH} 6$ and 7 yielded initial 4,4-AZOX concentrations of 0.78 and $0.60 \mathrm{mg} / \mathrm{L}$, respectively (Figures $7 \mathrm{a}$ and $\mathrm{b}$ ). This is unusual since the formation of azoxy compounds is reported to be favored at a $\mathrm{pH}>7$ (Funk et al. 1993). The diamino compounds appeared in solution almost immediately and were detected at the 30-min sampling period under all $\mathrm{pH}$ levels with concentrations lowest at $\mathrm{pH} 7$ (Figure 7b). At pH 6 and 8, concentrations of 4A-DNT were greater than those of 2A-DNT and persisted for a longer period (Figures $7 \mathrm{a}$ and c). In this study, the 


\section{Table 3 \\ Mass, mg, of Transformation Products above Detection Limits in Solution and Soil 11 Days after Addition of 15 mg TNT}

\begin{tabular}{|c|c|c|c|c|c|c|c|c|c|c|}
\hline \multirow[b]{2}{*}{ Eh, $\mathrm{mV}$} & \multirow[b]{2}{*}{$\mathrm{pH}$} & \multicolumn{2}{|c|}{ 2A-DNT } & \multicolumn{2}{|c|}{ 4A-DNT } & \multicolumn{2}{|c|}{ 2,4-DANT } & \multicolumn{2}{|c|}{ 4,4-AZOX } & \multirow{2}{*}{$\begin{array}{l}\text { Total } \\
\% \\
\text { Recovery }\end{array}$} \\
\hline & & Solution & Soil & Solution & Soil & Solution & Soil & Solution & Soil & \\
\hline \multirow[t]{3}{*}{-150} & 6 & 0 & 0 & 0 & 0 & 0 & 0 & 0 & 0 & 0 \\
\hline & 7 & 0 & 0 & 0 & 0 & 0 & 0 & 0 & 0.026 & 0.17 \\
\hline & 8 & 0 & 0 & 0.140 & 0 & 1.92 & 0.075 & 0 & 0.048 & 15.5 \\
\hline \multirow[t]{3}{*}{+150} & 6 & 0 & 0 & 0.962 & 0 & 1.48 & 0.086 & 0 & 0.035 & 17.1 \\
\hline & 7 & 0 & 0 & 1.03 & 0.026 & 0.151 & 0 & 0 & 0.345 & 10.4 \\
\hline & 8 & 0 & 0 & 0.541 & 0.037 & 0.640 & 0 & 0 & 0.467 & 11.3 \\
\hline \multirow[t]{3}{*}{+450} & 6 & 0 & 0 & 0.398 & 0 & 0 & 0 & 0 & 0.623 & 6.9 \\
\hline & 7 & 0.434 & 0 & 0.983 & 0 & 0.231 & 0 & 0 & 1.47 & 24.3 \\
\hline & 8 & 0 & 0 & 0.796 & 0.728 & 0.133 & 0 & 0 & 0.810 & 17.0 \\
\hline
\end{tabular}

2A-DNT and 4A-DNT had virtually disappeared after $24 \mathrm{hr}$ of incubation, whereas in the surface soil investigations these compounds were still in solution after 4 and 9 days of incubation (Price, Brannon, and Hayes 1997). The sequential reduction of 4A-DNT to 2,4-DANT was observed at $\mathrm{pH} 8$ in the aquifer soil (Figure 7c), paralleling results observed with surface soil under a wide range of $\mathrm{pH}$ conditions (Price, Brannon, and Hayes 1997).

Under moderately reduced conditions $(+150 \mathrm{mV}) \mathrm{pH}$ appeared to affect the appearance of TNT transformation products in solution. At pH 6 only monoamino compounds were detected (Figure 8a). At pH 7 and 8, 4,4-AZOX was detected in solution through $24 \mathrm{hr}$ at which time 2,4-DANT appeared in solution and reached a high concentration of $0.78 \mathrm{mg} / \mathrm{L}$ under $\mathrm{pH} 8.0$ conditions (Figures $8 \mathrm{~b}$ and $\mathrm{c}$ ).

Under oxidized conditions $(+450 \mathrm{mV})$ TNT remained in solution through 11 days. Greater numbers and higher concentrations of transformation products appeared in solution in reactors maintained at $\mathrm{pH} 6$ and 7 (Figures 9a and b). At $\mathrm{pH} 8$ 4A-DNT and 2,4-DANT were the only two products detected in solution (Figure 9c). 


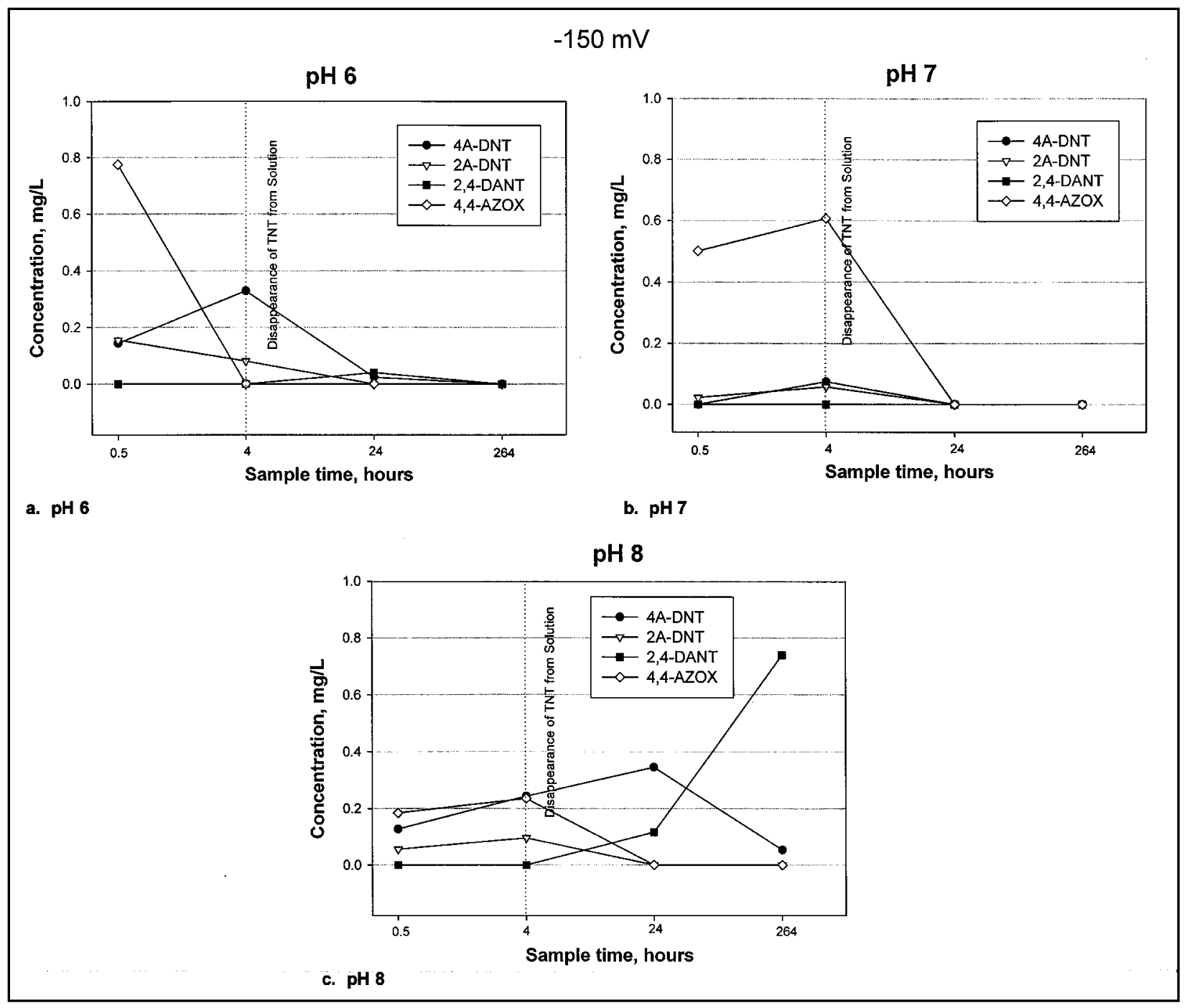

Figure 7. TNT and its transformation products in solution in the aquifer soil at each $\mathrm{pH}$ over time at $-150 \mathrm{mV}$

\section{Mass balance for $\mathrm{Eh} / \mathrm{pH}$ incubations}

Significant differences were observed in partitioning of the radioactivity between the soil and water in aquifer and surface soils. Most of the radioactivity remained in the aqueous phase of the aquifer soil tests under both highly reducing and oxidizing conditions. However, the majority of radiolabelled carbon in the surface soil test was found in the soil rather than in solution under both oxidized and reduced conditions (Table 4). These results indicate that the fate of TNT and its transformation products is quite different in aquifer and surface soils. 


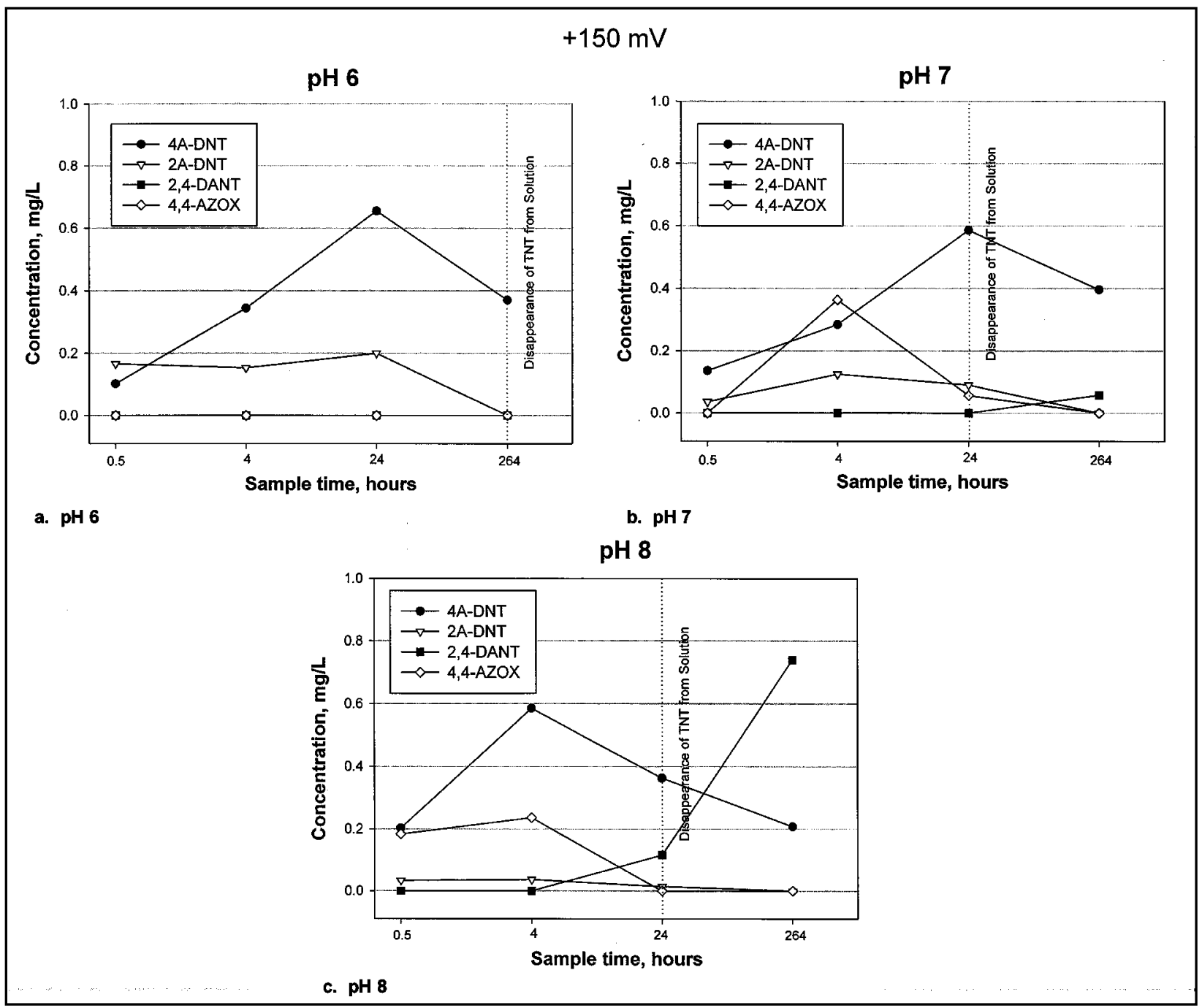

Figure 8. TNT and its transformation products in solution at each $\mathrm{pH}$ over time at $+150 \mathrm{mV}$

\section{Cation Adsorption}

Homoionic saturation of aquifer soils and clays had a marked effect on TNT adsorption coefficients (Table 5). Saturation of clays and aquifer soils with the weakly hydrated cations $\mathrm{K}^{+}$and $\mathrm{NH}_{4}{ }^{+}$resulted in increased adsorption of TNT compared with that of the strongly hydrated cation $\mathrm{Ca}^{++}$. Saturation with $\mathrm{Ca}^{++}$ resulted in values of the distribution coefficient $K_{d}$ much lower than those observed for the clay minerals and aquifer soils saturated with $\mathrm{K}^{+}$and $\mathrm{NH}_{4}{ }^{+}$. Saturation with $\mathrm{Ca}^{++}$resulted in values of $K_{d}$ consistently lower than those of the untreated material. These lower values of $K_{d}$ following saturation with $\mathrm{Ca}^{++}$ would result in higher solution TNT concentrations in the environment compared to those of the untreated material. 


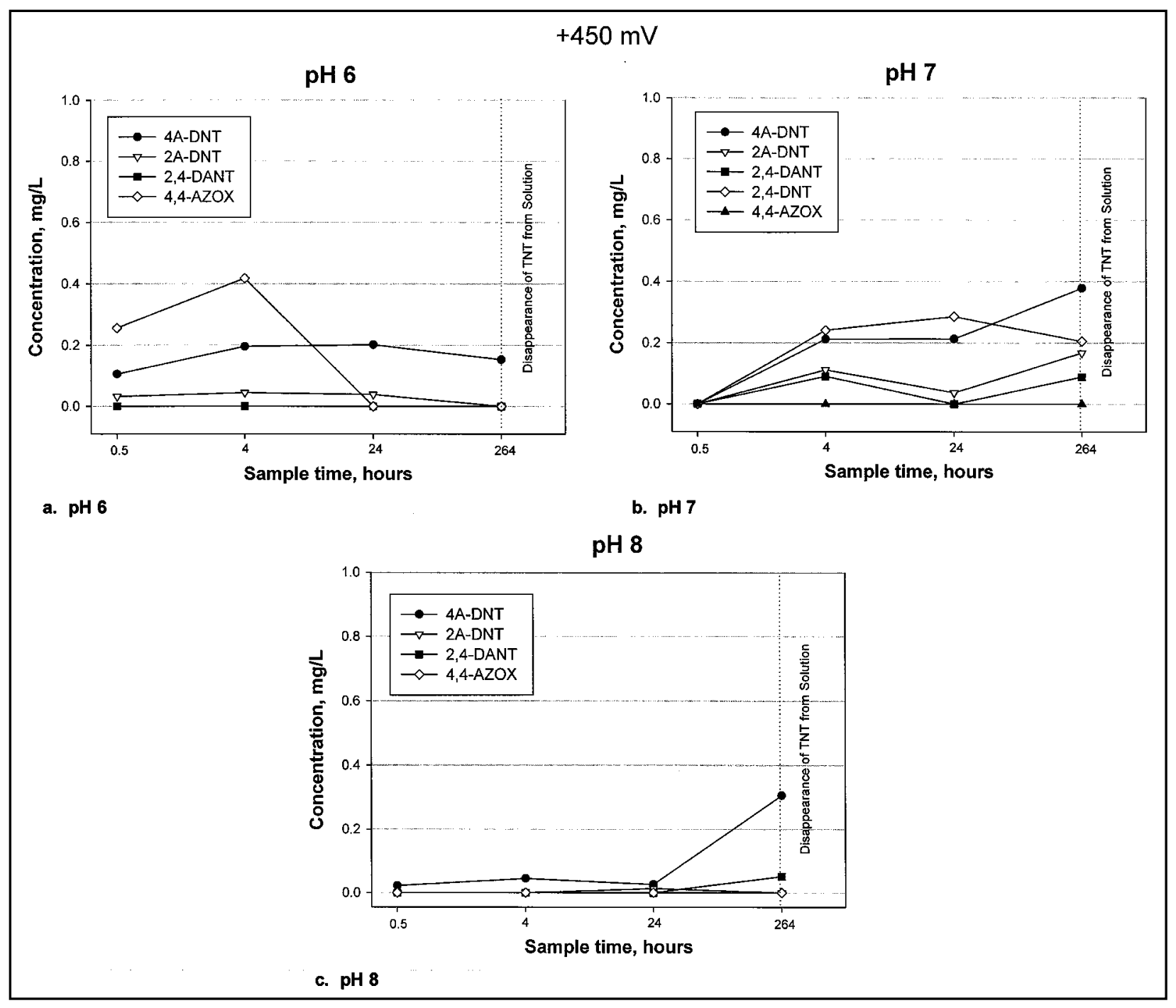

Figure 9. TNT and its transformation products in solution at each pH over time at $+450 \mathrm{mV}$

\begin{tabular}{|c|c|c|c|}
\hline \multicolumn{4}{|c|}{$\begin{array}{l}\text { Table } 4 \\
\text { Percent Recoveries of Radioactivity in Tests Conducted with an } \\
\text { Aquifer Soil and a Surface Soil }\end{array}$} \\
\hline \multirow[b]{2}{*}{ Treatment } & \multicolumn{3}{|c|}{ Phase } \\
\hline & Water & Soil & $\mathrm{CO}_{2}$ \\
\hline \multicolumn{4}{|c|}{ Aquifer Soil } \\
\hline$-150 \mathrm{mV}$ & 77 & 21 & 0.10 \\
\hline$+450 \mathrm{mV}$ & 65 & 52 & 0.94 \\
\hline \multicolumn{4}{|c|}{ Surface Soil } \\
\hline$-150 \mathrm{mV}$ & 9.6 & 82 & 0.09 \\
\hline$+450 \mathrm{mV}$ & 31 & 83 & 2.7 \\
\hline
\end{tabular}




\section{Table 5 TNT Distribution Coefficients $K_{d}$, $\mathbf{L} / \mathbf{k g}$, and Associated Linear Regression Coefficients $r^{2}$ for Homoionic and Untreated Aquifer Soils and Clays}

\begin{tabular}{|c|c|c|c|c|c|c|c|c|}
\hline \multirow[b]{2}{*}{ Soil } & \multicolumn{2}{|c|}{$\mathbf{K}^{+}$Saturated } & \multicolumn{2}{|c|}{$\mathrm{Ca}^{++}$Saturated } & \multicolumn{2}{|c|}{$\mathrm{NH}_{4}{ }^{+}$Saturated } & \multicolumn{2}{|c|}{ Untreated } \\
\hline & $K_{d}$ & $r^{2}$ & $K_{d}$ & $r^{2}$ & $K_{d}$ & $r^{2}$ & $K_{d}$ & $r^{2}$ \\
\hline TNT in LAAP-A & 26.4 & 0.96 & 0.11 & 0.56 & 19.1 & 0.96 & 1.09 & 0.95 \\
\hline TNT in LAAP-C & 65.5 & 0.98 & 0.35 & 0.99 & 78.8 & 0.99 & 1.06 & 0.96 \\
\hline TNT in LAAP-D & 165 & 0.999 & 1.19 & 0.997 & 179 & 0.996 & 1.67 & 0.98 \\
\hline TNT in Kaolinite & 7.02 & 0.96 & 0.25 & 0.92 & 3.48 & 0.96 & 0.33 & 0.97 \\
\hline TNT in Montmorillonite & 417 & 0.997 & 70.5 & 0.989 & 373 & 0.998 & 413 & 0.999 \\
\hline RDX in LAAP-D & 0.662 & 0.943 & 0.150 & 0.58 & 0.416 & 0.893 & 0.286 & 0.861 \\
\hline HMX in LAAP-D & 2.00 & 0.985 & 4.22 & 0.972 & 0.88 & 0.991 & 2.39 & 0.715 \\
\hline
\end{tabular}

These results demonstrate that the processes observed for pure clay minerals (Haderlein, Weissmahr, and Schwarzenbach 1996) are also operative in aquifer soils. The linear adsorption model adequately fit the data as shown by the high regression coefficients in Table 5. This is not unexpected since linear adsorption isotherms successfully describe the adsorption of explosives compounds on mineral surfaces and soils under conditions of low surface coverage (Haderlein, Weissmahr, and Schwarzenbach 1996; Pennington et al. 1999; Myers et al. 1998). Of the untreated soils and clays, only untreated montmorillonite possessed a $K_{d}$ comparable to that observed with the homoionic $\mathrm{K}^{+}$and $\mathrm{NH}_{4}{ }^{+}$material (Figure 10). This indicated that the untreated material was saturated with poorly hydrated cations. Saturation with $\mathrm{K}^{+}$and $\mathrm{NH}_{4}{ }^{+}$did not significantly increase TNT $K_{d}$ above that of untreated montmorillonite. However, $\mathrm{Ca}^{++}$saturation resulted in a $K_{d}$ well below those resulting from $\mathrm{K}^{+}$and $\mathrm{NH}_{4}{ }^{+}$saturation or the untreated montmorillonite.

Specific adsorption of RDX was increased by homoionic substitution with $\mathrm{K}^{+}$ and $\mathrm{NH}_{4}{ }^{+}$, but $\mathrm{HMX}$ adsorption decreased under these same conditions and increased with homoionic substitution of $\mathrm{Ca}^{++}$(Table 5). RDX adsorption on LAAP-D soils showed the same general trends as TNT (Figure 11), although the magnitude of increased adsorption is much greater for TNT than for RDX. Poorly hydrated cations such as $\mathrm{K}^{+}$and $\mathrm{NH}_{4}{ }^{+}$increased $\mathrm{RDX}$ adsorption relative to $\mathrm{Ca}^{++}$ saturated and untreated soil. Sorption of HMX showed trends opposite to those exhibited by TNT and RDX. Homoionic $\mathrm{K}^{+}$and $\mathrm{NH}_{4}{ }^{+}$saturation lowered adsorption of HMX compared to that of the untreated soil. Homoionic $\mathrm{Ca}^{++}$ saturation resulted in a doubling of HMX adsorption compared with all other treatments. The chemical structure and binding mechanism of HMX to the soil exchange complex apparently result in strongly hydrated cations such as $\mathrm{Ca}^{++}$ 


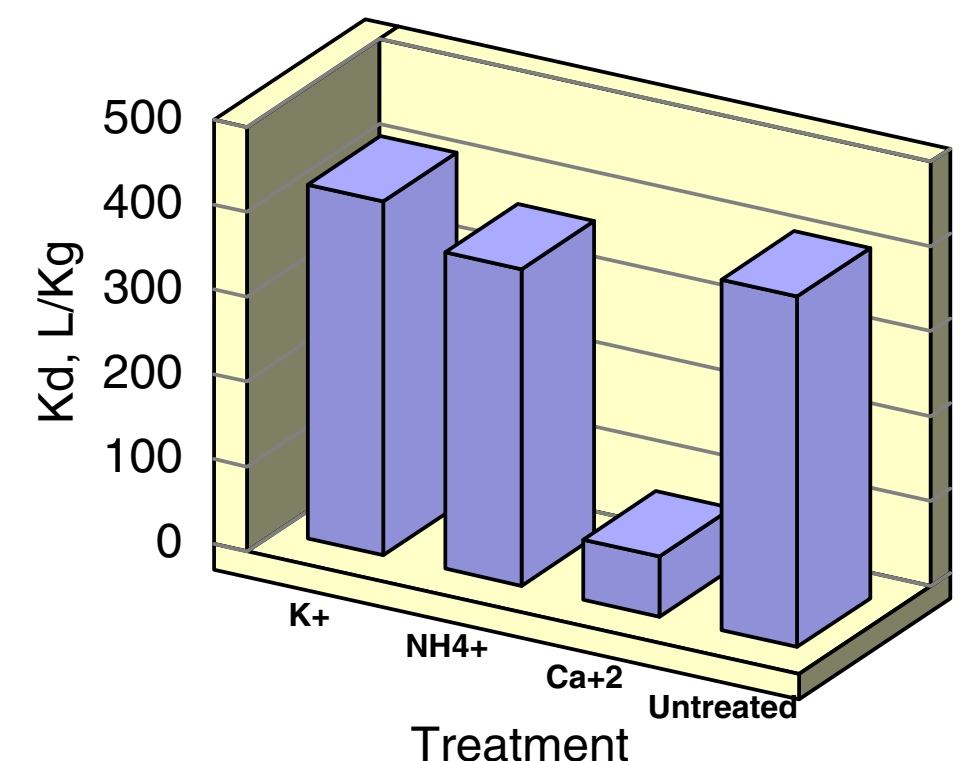

Figure 10. TNT sorption coefficients in homoionic montmorillonite treatments

increasing sorption. For TNT, sorption is increased in the presence of more weakly hydrated cations such as $\mathrm{NH}_{4}{ }^{+}$and $\mathrm{K}^{+}$. These aquifer soil results differ from those observed by Haderlein, Weissmahr, and Schwarzenbach (1996) for RDX adsorption by clay minerals where no apparent effects of cation substitution were noted.

Specific adsorption of TNT in homoionic $\mathrm{K}^{+}$and $\mathrm{NH}_{4}{ }^{+}$aquifer soils and clay minerals was highly correlated with cation exchange capacity (CEC), showing values of the linear regression coefficient $r^{2}=0.976$ and 0.993 , respectively (Figure 12). The strong relationship between TNT adsorption and CEC is not surprising in view of the relationship between CEC and TNT adsorption observed for a wide range of surface and aquifer soils (Brannon et al. 1999). Adsorption of nitroaromatic compounds such as TNT occurs primarily at the external surfaces of clay minerals (Haderlein, Weissmahr, and Schwarzenbach 1996), which CEC is apparently measuring. Untreated and homoionic $\mathrm{Ca}^{++}$aquifer soils and clay minerals did not display the strong relationship between TNT $K_{d}$ and CEC because of the anomalous behavior of the untreated and homoionic $\mathrm{Ca}^{++}$ montmorillonite. Relationships between TNT $K_{d}$ and CEC (excluding montmorillonite) were strong for homoionic $\mathrm{Ca}^{++}$aquifer soils and kaolinite $\left(r^{2}\right.$ $=0.976)$ and untreated aquifer soils and kaolinite $\left(r^{2}=0.64\right)$. The reasons for the anomalous behavior of homoionic $\mathrm{Ca}^{++}$and untreated montmorillonite are under investigation. 


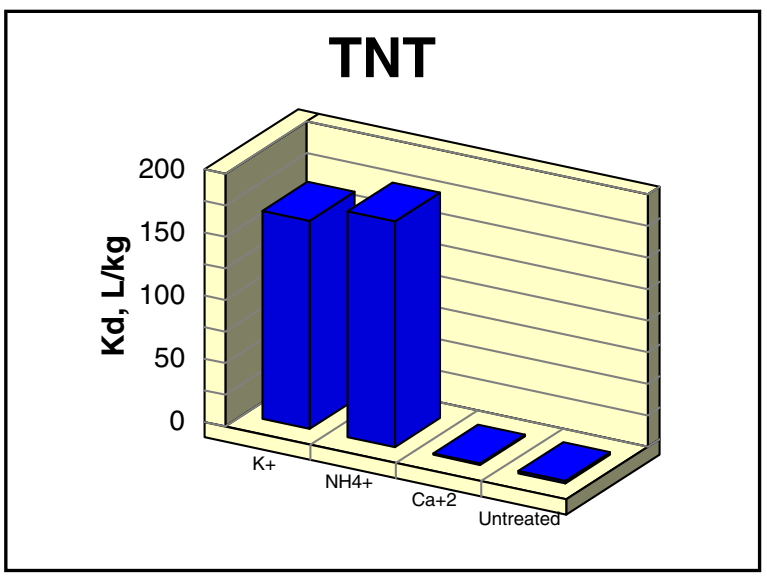

a. TNT

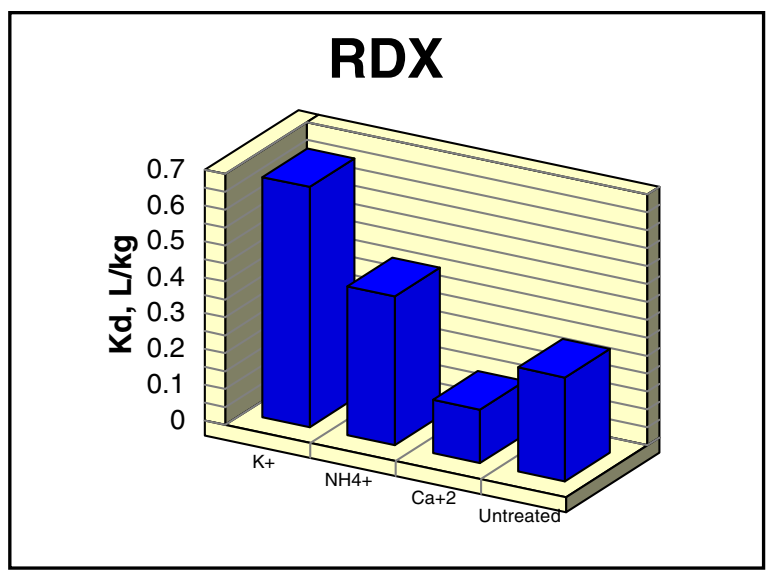

b. RDX

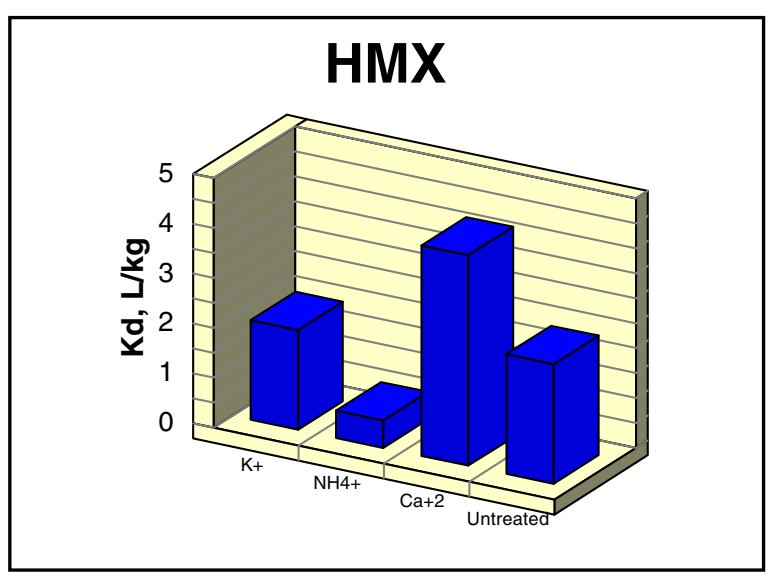

c. $\mathrm{HMX}$

Figure 11. TNT, RDX, and HMX sorption in homoionic and untreated LAAP-D soil 


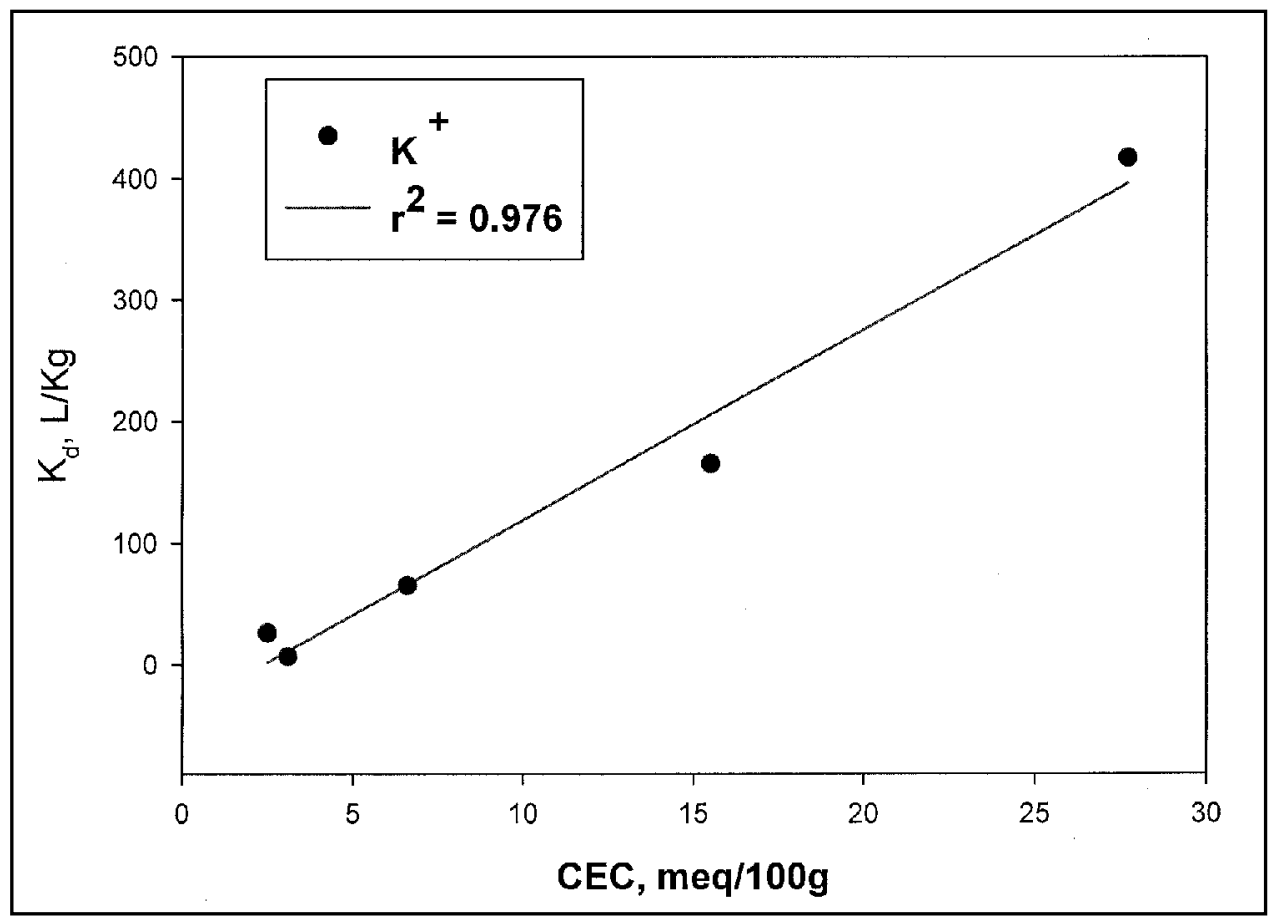

a. $\mathrm{K}^{+}$

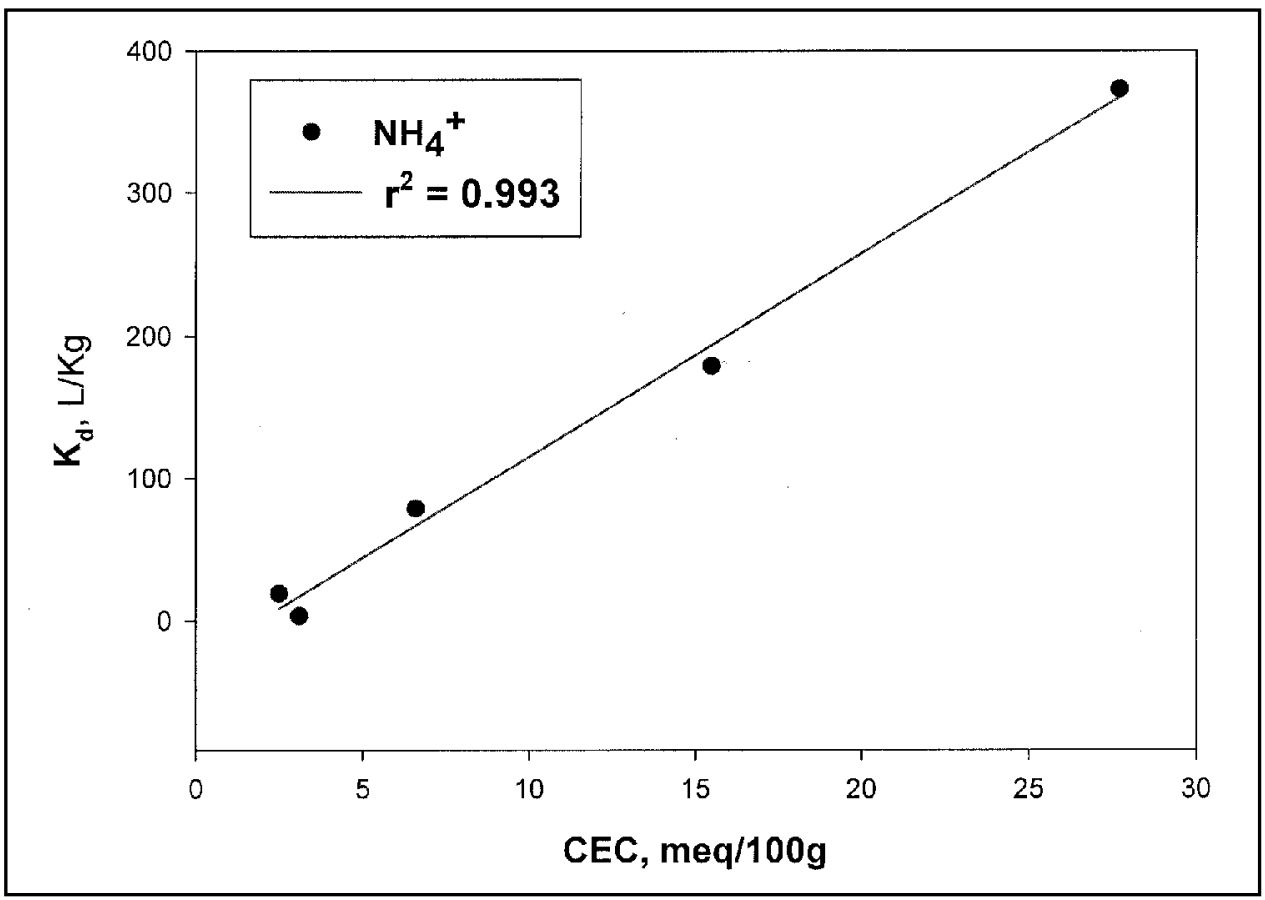

b. $\mathrm{NH}_{4}^{+}$

Figure 12. Correlation of TNT $\mathrm{K}^{+}$and $\mathrm{NH}_{4}{ }^{+}$distribution coefficients with $\mathrm{CEC}$ 


\section{Conclusions}

Glucose proved to be an energy source that could effectively drive the aquifer soil:water slurry to highly reducing $(-150 \mathrm{mV})$ conditions and maintain a low redox potential. TNT added to low-carbon aquifer soils amended with glucose was not stable under any Eh or $\mathrm{pH}$ conditions. Highly reducing conditions promoted rapid removal of TNT and its transformation products from solution compared with moderately reducing and oxidizing conditions. TNT persistence was greatest in unamended systems at moderately reducing and oxidizing conditions. The TNT transformation pathway in the aquifer soil favored production of 4A-DNT and 2,4-DANT compared with surface soil where pronounced production of 2A-DNT and 2,6-DANT in addition to 4A-DNT and 2,4-DANT was observed. As redox potential decreases, TNT disappearance from solution increases. In addition, anaerobic conditions promote the rapid disappearance of certain TNT transformation products and the appearance of others (in particular the diamino products) indicating the progression of the reduction process of TNT from a single nitro group to two nitro groups. This reduction appears to be regulated by higher $\mathrm{pH}$ conditions. An increased redox potential yielded lower initial concentrations of transformation products, and at an Eh of $+450 \mathrm{mV}, \mathrm{pH} \mathrm{8,} \mathrm{transformation} \mathrm{product} \mathrm{formation} \mathrm{was} \mathrm{inhibited.}$

Radioactivity recovered in $\left[{ }^{14} \mathrm{C}\right] \mathrm{TNT}$ mass balance tests was found primarily in the aqueous phase following incubation under both oxidized and reduced conditions. This distribution was in marked contrast to that observed in a surface soil where the great majority of the radioactivity was associated with soil organic matter. This change in distribution is likely a function of the lack of organic carbon available for covalent bonding with TNT transformation products. A comparison of the radioactivity equivalent of $\mathrm{C}^{14}$ in solution to the limited recovery of unlabeled TNT and its transformation products strongly suggests the existence of unidentified transformation products.

These results indicate that TNT in an aquifer soil with an added energy source will not persist as the parent compound. Transformation products will also disappear rapidly with higher concentrations of products remaining in solution under more oxidized conditions.

Homoionic saturation of aquifer soils significantly affected TNT adsorption. Saturation of these soils with weakly hydrated cations $\left(\mathrm{K}^{+}\right.$and $\left.\mathrm{NH}_{4}^{+}\right)$resulted in increased TNT and RDX sorption to the aquifer soils. Saturation with the stronger hydrated cation $\left(\mathrm{Ca}^{++}\right)$resulted in $K_{d}$ lower than those in untreated material indicating that higher TNT and RDX solution concentrations would 
occur in the environment. HMX showed a significantly different trend with sorption increasing when the soil was treated with a strongly hydrated cation. 


\section{References}

Brannon, J. M. (1983). "The transformation, fixation, and mobilization of arsenic and antimony in contaminated sediments," Ph.D. diss., Louisiana State University, Baton Rouge, LA.

Brannon, J. M., Deliman, P., Ruiz, C., Price, C., Qasim, M., Gerald, J. A., Hayes, C., and Yost, S. (1999). "Conceptual model and process descriptor formulations for fate and transport of UXO," Technical Report IRRP-99-1, U.S. Army Engineer Waterways Experiment Station, Vicksburg, MS.

Funk, S. B., Roberts, D. J., Crawford, D. L., and Crawford, R. L. (1993). "Initial phase optimization for bioremediation of munition compound-contaminated soils," Applied Environmental Microbiology 59, 2171-2177.

Haderlein, S. B., Weissmahr, K. W., and Schwarzenbach, R. P. (1996). "Specific adsorption of nitroaromatic explosives and pesticides to clay minerals," Environmental Science and Technology 30, 612-622.

Jackson, M. L. (1958). Soil chemical analysis. Prentice-Hall, Englewood Cliffs, NJ.

Kaplan, D. L., and Kaplan, A. M. (1982). "Thermophilic biotransformations of 2,4,6-trinitrotoluene under simulated composting conditions," Applied and Environmental Microbiology 44, 757-760.

Myers, T. E., Brannon, J. M., Pennington, J. C., Townsend, D. M., Davis, W. M., Ochman, M. K., Hayes, C. A., and Myers, K. T. (1998). "Laboratory studies of soil sorption/transformation of TNT, RDX, and HMX," Technical Report IRRP-98-8, U.S. Army Engineer Waterways Experiment Station, Vicksburg, MS.

Patrick, W. H., Jr., Williams, B. G., and Moraghan, J. T. (1973). “A simple system for controlling redox potential and $\mathrm{pH}$ in soil suspensions," Soil Science Soc. Am. Proc. 37, 331-332.

Pennington, J. C., and Patrick, W. H., Jr. (1990). "Adsorption and desorption of 2,46-trinitrotoluene by soils," Journal of Environmental Quality 19, 559-567. 
Pennington, J. C., Gunnison, D., Harrelson, D. W., Brannon, J. M., Zakikhani, M., Clark, J. U., Fredrickson, H., Myers, T., Jenkins, T. F., Perkins, E., Hayes, C. A., Ringelberg, D., and Townsend, D. M. (1999). "Natural attenuation of explosives in soil and water systems at Department of Defense sites: Interim report," Technical Report EL-99-8, U.S. Army Engineer Waterways Experiment Station, Vicksburg, MS.

Price, C. B., Brannon, J. M., and Hayes, C. (1997). "Effect of redox potential and $\mathrm{pH}$ on TNT transformation in soil-water slurries," Journal of Environmental Engineering, October 1997, 988-992.

Price, C. B., Brannon, J. M., and Yost, S. L. (1998). "Transformation of RDX and HMX under controlled Eh/pH conditions," Technical Report IRRP-98-2, U.S. Army Engineer Waterways Experiment Station, Vicksburg, MS.

U.S. Environmental Protection Agency. (1982). "Methods for chemical analysis of water and wastes," EPA 600/4/82-055, Cincinnati, OH.

. (1990). "Test methods for evaluating soild wastes," SW-846 Method 8330, Washington, DC.

Weissmahr, K. W., Hildenbrand, M., Schwarzenbach, R. P., and Haderlein, S. B. (1999). "Laboratory and field scale evaluation of geochemical controls on groundwater transport of nitroaromatic ammunition residues," Environmental Science and Technology 33, 2593-2600. 
Public reporting burden for this collection of information is estimated to average 1 hour per response, including the time for reviewing instructions, searching existing data sources, gathering and maintaining the data needed, and completing and reviewing the collection of information. Send comments regarding this burden estimate or any other aspect of this collection of information, including suggestions for reducing this burden, to Washington Headquarters Services, Directorate for Information Operations and Reports, 1215 Jefferson Davis Highway, Suite 1204, Arlington, VA 22202-4302, and to the Office of Management and Budget, Paperwork Reduction Project (0704-0188), Washington, DC 20503.

\begin{tabular}{|l|l|l|l}
\hline 1. AGENCY USE ONLY (Leave blank) & 2. $\begin{array}{l}\text { REPORT DATE } \\
\text { September } 2000\end{array}$ & $\begin{array}{l}\text { 3. } \\
\text { REPORT TYPE AND DATES COVERED } \\
\text { Final report }\end{array}$
\end{tabular}

\section{TITLE AND SUBTITLE}

5. FUNDING NUMBERS

Adsorption and Transformation of Explosives in Low-Carbon Aquifer Soils

6. AUTHOR(S)

Cynthia B. Price, James M. Brannon, Sally L. Yost, Charolett A. Hayes

7. PERFORMING ORGANIZATION NAME(S) AND ADDRESS(ES)

U.S. Army Engineer Research and Development Center, Environmental Laboratory

3909 Halls Ferry Road, Vicksburg, MS 39180-6199;

DynTel Corporation, 17 Executive Park Drive, Suite 115, Atlanta, GA 30329;

AScI Corporation, 1365 Beverly Road, McLean, VA 22101

9. SPONSORING/MONITORING AGENCY NAME(S) AND ADDRESS(ES)

U.S. Army Corps of Engineers

Washington, DC 20314-1000

8. PERFORMING ORGANIZATION REPORT NUMBER

ERDC/EL TR-00-11

10. SPONSORING/MONITORING AGENCY REPORT NUMBER

\section{SUPPLEMENTARY NOTES}

12a. DISTRIBUTION/AVAILABILITY STATEMENT

12b. DISTRIBUTION CODE

Approved for public release; distribution is unlimited

13. ABSTRACT (Maximum 200 words)

Disposal operations from the manufacturing processes of the explosives 2,4,6-trinitrotoluene (TNT), 1,3,5-trinitro-1,3,5-hexahydrotriazine (RDX), and octahydro-1,3,5,7-tetranito-1,3,5,7-tetrazocine (HMX) have resulted in the contamination of soil and groundwater at many active and inactive munitions sites. One option to be investigated for site cleanup is natural attenuation of these contaminants. The potential success of this option depends upon the ability of low-carbon aquifer materials to adsorb and transform explosive contaminants. Therefore, an understanding of the processes that control the mobility and transformation of explosives in low-carbon aquifer soils is needed to improve evaluation of natural attenuation in aquifers.

The objective of this study was to investigate the effects of environmental conditions such as redox potential, $\mathrm{pH}$, and groundwater quality on sorption and transformation of explosives in low-carbon aquifer soils.

Laboratory investigations addressing the effects of redox potential and $\mathrm{pH}$ on TNT transformation in an aquifer soil were conducted by testing at three separate redox potentials and three $\mathrm{pH}$ levels. An 18:1 (water:soil) suspension spiked with $15 \mathrm{mg}$ TNT was used. Results indicated that TNT added to a low-carbon aquifer soil amended with an additional energy source, glucose, was not stable under any Eh or $\mathrm{pH}$ conditions. Highly reducing conditions promoted more rapid removal of TNT and its transformation products.

(Continued)

14. SUBJECT TERMS

Aquifer soil

$\mathrm{pH}$

Groundwater

RDX sorption

HMX sorption

Redox potential

15. NUMBER OF PAGES

Homoionic saturation

TNT transformation

17. SECURITY CLASSIFICATION OF REPORT UNCLASSIFIED
18. SECURITY CLASSIFICATION OF THIS PAGE UNCLASSIFIED
19. SECURITY CLASSIFICATION OF ABSTRACT 
13. (Concluded)

Three aquifer soils and two clays were tested for the effects of homoionic substitution on adsorption of TNT. Additional sorption tests with RDX and HMX were conducted using one aquifer soil. TNT adsorption to aquifer soils was seen to be significantly affected by homoionic saturation. Saturation of the soils with weakly hydrated cations $\left(\mathrm{K}^{+}\right.$and $\left.\mathrm{NH}_{4}^{+}\right)$resulted in increased TNT and RDX sorption, but decreased sorption was seen with $\mathrm{Ca}^{++}$saturation. HMX showed a significantly different trend with increasing sorption being seen when the soil was treated with a strongly hydrated cation $\left(\mathrm{Ca}^{++}\right)$. 